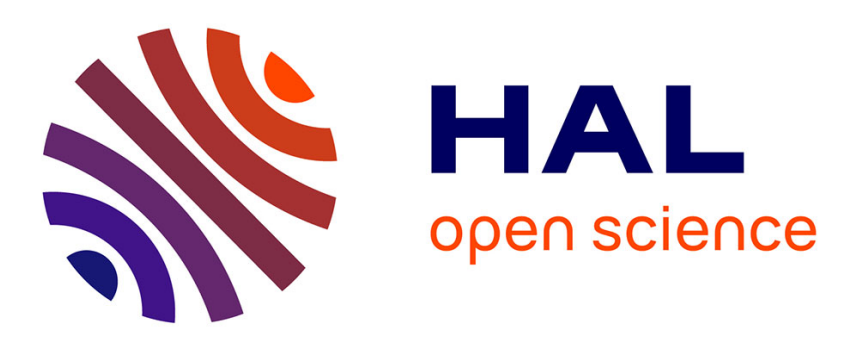

\title{
Daily forecast of solar thermal energy production for heat storage management
}

Sylvain Rodat, Christian Tantolin, Xavier Le Pivert, Sylvain Lespinats

\section{To cite this version:}

Sylvain Rodat, Christian Tantolin, Xavier Le Pivert, Sylvain Lespinats. Daily forecast of solar thermal energy production for heat storage management. Journal of Cleaner Production, 2016, 139, pp.86-98. 10.1016/j.jclepro.2016.08.019 . hal-02567219

\section{HAL Id: hal-02567219 https://hal.science/hal-02567219}

Submitted on 12 May 2020

HAL is a multi-disciplinary open access archive for the deposit and dissemination of scientific research documents, whether they are published or not. The documents may come from teaching and research institutions in France or abroad, or from public or private research centers.
L'archive ouverte pluridisciplinaire HAL, est destinée au dépôt et à la diffusion de documents scientifiques de niveau recherche, publiés ou non, émanant des établissements d'enseignement et de recherche français ou étrangers, des laboratoires publics ou privés. 


\title{
9985 words
}

\section{Daily forecast of solar thermal energy production for heat storage management}

\author{
Sylvain Rodat ${ }^{1}$, Christian Tantolin ${ }^{1}$, Xavier Le Pivert ${ }^{2}$, Sylvain Lespinats ${ }^{3}$ \\ 1 Univ. Grenoble Alpes INES BP 332, 50 avenue du Lac Léman, F-73375 Le-Bourget-du-lac, France. \\ CEA-LITEN High Temperature Solar Systems Laboratory, F-38054 Grenoble, France. \\ Tel : (+33)4 797921 20, sylvain.rodat@cea.fr \\ 2 SteadySun, Savoie Technolac - BP 40328, Bâtiment « Hélios », 60 avenue du Lac Léman F-73377 Le-Bourget-du-lac, \\ France. \\ 3 Univ. Grenoble Alpes INES BP 332, 50 avenue du Lac Léman, F-73375 Le-Bourget-du-lac, France. \\ CEA-LITEN, Photovoltaic Systems Laboratory F-38054 Grenoble, France.
}

\section{Highlights}

- A method that forecasts the Direct Normal Irradiance is defined.

- A thermal model of a solar thermal power plant is also proposed.

- These two models enhanced by learning procedures are combined.

- Daily forecasts of the thermal power output of a solar plant are performed.

\section{Abstract}

Solar energy offers a renewable source of power but its fluctuating nature raises concerns about the electrical grid balancing. Network regulators have to estimate the upcoming production to match supply with demand; consequently, power plant operators may be asked to provide accurate forecasts. Planning the thermal or electrical output of solar power plants is thus highly required to ensure a stable power chain supply. This paper presents a solution that couples a meteorological model with a solar power plant performance model. The power output is predicted $24 \mathrm{~h}$ ahead in the case of a solar Fresnel power plant. The required Direct Normal Irradiance is inferred from the global horizontal irradiance; the thermal production is evaluated from an optical and thermal model. Our approach has been validated on a $1000 \mathrm{~m}^{2}$ Fresnel power plant, paving the way for model-based storage strategy. 
Keywords: meteorological forecast, direct normal irradiance forecast, Fresnel power plant model, control strategy, learning procedure.

\section{Introduction}

The technologies to harness the sun power are spreading worldwide: solar energy is taking an important role into the energy mix. Yet, the sky cannot always be cloudless. The weather is intrinsically fluctuating and chaotic, and so is the incoming solar radiation. These instabilities can threaten the good balancing of the whole electrical grid. To cope with the solar energy integration challenge, production patterns must be anticipated (Lin and Pai, 2015; Sáez-Martínez, et al., 2015). Several tools have already been developed in order to forecast the production of photovoltaic plants (Bacher et al., 2009; Lorenz et al., 2011; Qazi, et al., 2015). In particular, the CEA/INES and Steadysun are involved in the development of a day-ahead forecasting tool dedicated to the photovoltaic production (Lespinats et al., 2011). In the present paper, the method is extended to solar thermal power plants. This technology is based on the conversion of direct solar radiations into thermal energy. To do so, large mirrors concentrate the solar energy. On the focal point, the receiver reaches high temperatures that can be transferred to a fluid. Then, the collected thermal energy can either be used to run a turbine or can be stored. The power plant operators have to choose one of the two options, their decision must take into account both the weather forecast and the electricity selling price. Concentrated solar energy is currently increasing its share in the energy mix and the market rules will most probably change giving more value for storage capacities in the future. A power forecasting tool will subsequently become necessary.

For instance, to increase the profitability of a solar plant located in France, the best production time slot appears to be around $20 \mathrm{~h}$ according to the typical hourly electricity prices shown in Fig. 1 (http://clients.rtefrance.com). In the evening, the demand for electricity increases, thus its price rises. To help operators in their choice, the forecasting model has to estimate the Direct Normal Irradiance (DNI) (as opposed to photovoltaic production that only requires global irradiance). Several papers have already been published about DNI forecast (see section 3.1), but the combination with real solar power plant data is a step forward. Our tool is designed to directly forecast the output of Concentrated Solar Power (CSP) plants. Along with DNI, the external temperature is also considered since it influences the performance of CSP plants, especially thermodynamic cycle performances (Muñoz et al., 2012). The results are checked against 
experimental results on a $50 \mathrm{~kW}_{\text {el }}$ Fresnel prototype, constructed to validate an industrial project. Basically, the system is composed of a Fresnel system concentrating solar power onto receivers cooled by thermal oil. The maximum working temperature is $300{ }^{\circ} \mathrm{C}$. This type of system is envisioned to run an Organic Rankine Cycle to produce electricity. Our prototype provides an innovative and experimental testing platform, whose results are exploited to improve the models. To the best of our knowledge, this paper is the first attempt to predict thermal output of a CSP plant based on weather forecasts. Our tool is an important step to cope with electrical grid instability induced by solar electricity production. Grid balancing can be eased if accurate production forecasts are available, paving the way for solar energy deployment.

Section 2 provides an overview of the method and describes experimental site locations and the experimental equipment. Section 3 is dedicated to meteorological, physical and statistical models. Section 4 describes the evaluation procedure. In section 5, the whole forecasting tool is validated against experimental data and section 6 opens the discussion about production optimization.

\section{Experimental setup and forecasting methods}

\subsection{Method overview}

The objective of this paper is to present an original forecasting tool. The tool takes advantage of meteorological forecasts and benefits from empirical, physical and learned models. Fig. 2 shows a diagram summing up our approach with references to the section where detailed explanations can be found. Actual measurements are described in section 2.2, input meteorological forecasts are given in section 2.3 , the radiation decomposition model is presented in section 3.1 , section 3.2 is dedicated to optical and thermal models and section 3.3 shows learned models.

The tool works in two phases. The first one is the "forecasting phase": when a meteorological forecast is available, the various models are used to perform a new production forecast. The second mode is the "learning phase": on a daily basis, the measurements are compared to forecasts and the model can be improved.

Our system combines physical models and learned features. Unlike full machine-learning systems, we can follow the proceedings of the forecast (and the learning as well). In the case of poor results, the model-based approach lets us identify the part of the algorithm responsible for the error. Moreover, it gives the possibility 
to separate the influence of various parameters. For example, during the installation shut down, thermal losses can be especially highlighted. The learning procedures make the forecasts more and more accurate.

It must be kept in mind that the models are based on several parameters provided by the plant operator once for all. Although learning algorithms may be able to apply some corrections, our results depend on the trustworthiness of the parameters of the plant initially given.

In the present paper, the objective is to forecast on a given day d (typically at $16 \mathrm{~h}$ ) the pattern of production of a plant for day $\mathrm{d}+1$ from $0 \mathrm{~h}$ to $24 \mathrm{~h}$ (with a 1 minute time step). This choice comes from the electricity regulation rules in France. Obviously, forecasts can be obtained for different temporal horizons. Typically, the system performs two-day ahead forecasts with updates every 6 hours (i.e. every time a new meteorological forecast is available).

The present developments benefit from a pre-existent tool originally designed to forecast the production of photovoltaic plants (Lespinats et al., 2011). File format and program structure were kept unchanged. However, the DNI forecasts and the solar plant model were added. The learning algorithms were adapted accordingly.

\subsection{Sites and measurements}

\subsubsection{Main site: Cadarache}

The Fresnel prototype is located in Cadarache (Southern France - latitude: $43.69^{\circ}$, longitude: $5.76^{\circ}$ ), not far from Marseille where the first Fresnel prototype was built by Giovanni Francia (Francia, 1968). This place noted CAD in the following - ensures a good solar resource according to Suri et al. (2009) (Fig. 3). The resource is estimated to reach what can be called the CSP threshold $\left(2000 \mathrm{kWh} /\left(\mathrm{m}^{2} \times\right.\right.$ year $\left.)\right)$. The system (Fig. 4) is composed of a round trip solar field that permits to have the field output and input on the same side thus limiting the piping and thermal losses. Each of the two fields (one backward and one forward) is composed of ten rows of mirrors $\left(50 \mathrm{~m}\right.$ long). Thus, the total solar field is made of $1000 \mathrm{~m}^{2}$ of north-south oriented reflectors. The heat transfer fluid is a synthetic oil that handles the exit temperature of $300{ }^{\circ} \mathrm{C}$. An Organic Rankine Cycle along with a thermocline thermal storage (Bruch et al., 2012) give the opportunity to test the combination of all the main parts of a solar thermal plant. 
Temperature measurements are carried out with high precision calibrated platinum resistance temperature sensors (uncertainty of $+/-0.6^{\circ} \mathrm{C}$, ANSI Z540-1-1994) and the flowrates are measured accurately by Coriolis-type flowmeters (precision of $+/-0.1 \%$ of the measure, ISO 17025). The plant is also equipped with a Kipp\&Zonen CHP1 Pyrheliometer (First Class ISO 9060) for on-site DNI measurements in the spectral range 200 to $4000 \mathrm{~nm}$ with an expected daily uncertainty of $1 \%$ according to the manufacturer. The system is washed weekly or more if a special meteorological event occurs. The measurements are also redundant since another similar device is set at a distance of about $1 \mathrm{~km}$ from our DNI reference. Temporal resolution is 2 seconds. This equipment ensures precise experimental heat balances. DNI measurements are available from the $31 / 03 / 2011$ to the $31 / 02 / 2013$. The Gi (Global irradiance on a surface oriented toward South and with a $35^{\circ}$ tilt) was also measured during the same period (the sensor is a Fraunhofer ISE, mono-Si reference cell). All sensors are calibrated once a year by organisations certified by the French Cofrac accreditation body in relation with the International Bureau of Weights and Measures.

\subsubsection{Second site: INES}

The DNI is measured at a second site in France near Chambery in the Alps (latitude: $45.64^{\circ}$, longitude: 5.87 ${ }^{\circ}$ ). DNI measurements are available from the $17 / 06 / 2013$ to the $27 / 10 / 2013$. The Ghi (Global horizontal irradiance) is also evaluated.

\subsubsection{Additional site (Spain)}

Another site in the south of Spain for which DNI and Ghi measurements are available has been used in the present study. However, we can neither provide the location nor the measurement probe because the owner of the measurements wants to keep them confidential. Only the evaluation of the forecast will be disclosed.

\subsection{Meteorological input}

The actual system uses freely available GFS (Global Forecast System) data from NOAA (US National Oceanic and Atmospheric Administration), but any other data have already been tested (including forecasts from "Meteo France" (French meteorological administration www.meteofrance.com) or from ECMWF (European Centre for Medium-Range Weather Forecasts www.ecmwf.int)). Meteorological inputs are Ghi forecasts and ambient temperature. The model part dealing with temperature forecasts is not detailed here since it is a well-known meteorological science (Taylor and Leslie, 2005; Hagedorn et al., 2008). Here, no additional information than NWP (Numerical Weather Prevision) forecasting of global irradiance is 
taken into account because we aim at proposing a tool able to perform forecasts all around the world. Neither satellite nor in situ images are considered yet. However, satellite images and/or sky images could help to improve the forecasts, especially for short term forecasts (Heinemann et al., 2006; Lespinats et al. 2014, Law et al. 2014). Obviously, such input could be substituted to NWP data.

\section{Models}

\subsection{Estimation of DNI from Ghi}

GFS only gives access to an estimation of future Global horizontal irradiance (Ghi), but no information about direct normal irradiance is available. Several authors developed various methods to deal with this lack of information. The reader can refer to the in-depth review written by Law et al. (2014).

In order to estimate the upcoming DNI (Direct Normal Irradiance) from Ghi forecasts, Marquez and Coimbra (2011) develop an artificial neural network approach; Lara-Fanego et al. (2012) use the Ruiz-Arias et al. (2011) procedure which takes account of the landscape features; Breitkreuz et al. (2009) and SchroedterHomscheidt et al. (2011) integrate additional air quality forecasts (from the EURAD forecasts http://www.eurad.uni-koeln.de); Romeo et al. (2011) exploit support vector machine and enrich the inputs with satellite images; Hansen et al. (2012) also claim to perform similar work but their procedure is not disclosed.

The ability of our DNI forecasting tool to perform forecasts whatever the location of the plant around the world is of main concern. Conversely, the techniques described in the literature have been tested in a few use cases: one single site in California (USA) for Marquez et al. (2011); four sites in Andalousia (Spain) for Lara-Fanego et al. (2012) and one site in New Mexico (USA) for Hansen et al. (2012). However, the irradiance decomposition is known to be hardly generalizable. The process developed in (Breitkreuz et al. 2009) was tested on a high number of sites (121 European sites -mainly in Germany, UK and Spain), but because the EURAD forecasts are not available in the southern hemisphere, this method cannot be applied all around the world. Much more studies can be found about the forecasts of global horizontal irradiance (Mellit, 2008) or photovoltaic plant production (Espinar et al. 2010; Remund and Müller 2012) from NWP data.

Several alternatives to the NWP based models can be considered. In particular, satellite images or sky images taken in situ could be used instead. Such inputs can significantly ease the computations because the decomposition between direct and diffuse irradiance is not necessary anymore. Methods that forecast the 
global horizontal irradiance from satellite images were developed, especially by (Hammer et al. 2003 and Marquez et al. 2013a). Marquez and Coimbra (2013b) published a method so as to forecast the DNI from sky images. Recently, some authors use "black-box" time series to forecast the DNI (Dazhi et al. 2012), the direct horizontal irradiance (Mellit et al. 2010) or the Ghi (Mellit, 2008). There are some limitations to be mentioned concerning our experience on these purely "black-box" methods (Artificial Neural Networks for example). On the one hand, the weather is known to be chaotic; on the other hand, the cost functions used in order to evaluate the efficiency of a given forecast are arbitrary (see section 4); consequently, the distribution of possible situations is wide and the best fit may vary a lot depending on the chosen cost function. The resulting forecasts are often very unsmooth. Consequently, the capacity to forecast the quick variation for a long time ahead (one day for example) is unlikely. These shapes may come from specific cost functions and/or specific data rather than from physical behaviors. This phenomena must not be neglected because it affects the reliability of the results. Many other empirical methods are often used to estimate the DNI from Ghi - see (Dervishi and Mahdavi, 2012; Yang et al. 2013) for finer details.

In the following, our DNI forecasts are based on the decomposition of the forecasted Ghi given by the famous Erbs model (Erbs et al. 1982). Our choice is based on tests achieved on various datasets of the literature (Dervishi and Mahdavi, 2012; Yang et al. 2013). So, the NWP provides the forecasted Global Horizontal Irradiance, which can then be converted into forecasted Direct Horizontal Irradiance by the Erbs model. Eventually, the required $D N I_{F n w p}$ is deduced assuming that the relation between horizontal and direct irradiance is purely geometric.

\subsection{Fresnel performance model}

Various models that forecast the thermal and electrical outputs of solar plants have already been discussed. Most of the time, they consist in hourly simulations. For example, it is the case of the System Advisor Model, developed and distributed by the National Renewable Energy Laboratory (USA) that allows the simulation of systems such as photovoltaic or CSP plants (SAM (2011)) available online: https://www.nrel.gov/analysis/sam/). Other models are developed internally by industrial actors (Alliotte, 2011) or by research institutes. Manzolini et al. (2011a, 2011b) work on an Excel/VBA model named PATTO. This model was especially used for comparison purposes between different solar plant configurations (Giostri 2012). No storage is included yet as in Al Soud et al (2009). Dynamic libraries were 
also written with Modelica (ThermoSysPro library, available online: http://www.eurosyslib.com/librairies/WP5\%20-

\%20Thermofluid/WP\%205.3\%20Power\%20Plant\%20Thermofluids\%20Library.htm)

or

TRNSYS

(http://sel.me.wisc.edu/trnsys/trnlib/stec/stec.htm). The ANDASOL 2 solar power plant was also studied with a Wolfram's Mathematica 7 model by Garcia et al. (2011). Moreover, Powell and Edgar (2012) published a dynamic model and control of a solar thermal power plant with thermal energy storage. More details about modelling tools can be found in Ho (Ho, 2008). Finally, a standardization of the modelling approaches and methodology is under consideration through the GUISMO project (Guidelines CSP Performance Modeling) (http://www.solarpaces.org/Tasks/Task1/modelingguidelines.htm).

On the one hand, the short term production forecasts are very important for the control of the solar field parameters (heat transfer fluid temperature, flow rate and pressure). On the other hand, it is also of great interest to get longer term forecasts in order to manage the storage process. Since this work aims at defining a long term (24 h) control strategy, a simple model improved from Selig (2011) was developed and validated on the prototype. It consists of two main modules: an optical efficiency matrix and a polynomial thermal model of the receiver. The first tool determines the flux that is expected at the window of the receiver; the thermal model calculates how much thermal power can be transferred to the heat transfer fluid. The presented work only deals with forecasting thermal output from the solar field. It must be highlighted that a special care is paid to restrict the number of parameters used to describe the thermodynamic plant in sake of simplicity. The goal is to develop a convenient tool able to easily take into account new plants. For that reason, a trade-off between efficiency of the model and the number of required parameters is made. The main parameters are: the position of the plant (latitude and longitude), the time, the surface of the mirrors, the DNI, the ambient temperature, the optical efficiency matrix, the polynomial expression of the receiver thermal efficiency and the default input and output temperatures. The turbine and storage are still under study and will not be addressed in the following.

\subsubsection{Optical model}

An optical efficiency matrix is established for longitudinal and transversal angles defining the sun position throughout the year. The angle step is $10^{\circ}$. A $10^{\circ}$ resolution is an appropriate resolution according to the standard EN12975 published by (Kovacs, 2012). Many works dealing with Fresnel performance modelling follow this recommendation (Morin et al., 2012; Selig et al., 2011; Nixon et al., 2013) since it offers a good 
compromise between computational efforts and result precision. This matrix is calculated with Zemax ray tracing model (Radiant Zemax, V12). It includes the real 3D (three-dimensional) geometry of the solar field (receiver height, mirror width and shape, reflectivity of the mirror as a function of the incident angle, space between mirrors, tracking errors, longitudinal losses). It is computed for a DNI of $1000 \mathrm{~W} / \mathrm{m}^{2}$. The optical model also includes the reflectivity of the receiver window since this optical property highly depends on the incidence angle. As a consequence, the matrix gives the flux that reaches the receiver window and that is not reflected, for all possible sun positions.

\subsubsection{Receiver model}

Our receiver is similar to the trapezoidal cavity exposed by Singh et al (2010). A simplified scheme is presented in Fig. 5. It is composed of an insulated cavity closed by a window at the bottom and crossed by several tubes. The window permits to limit heat losses but leaves most of solar radiations reaching the tube. The top of the cavity is insulated in order to limit thermal losses to the environment. The following model is mainly derived from the work of Forristall (2003) who proposed a simplified model for parabolic trough receiver.

The main assumptions are listed hereafter:

- Surfaces radiate isotropically;

- In the visible spectrum, only the first reflection is taken into account and the next ones are neglected;

- In the IR (InfraRed) spectrum, the multiple reflections are considered through the calculation of a net exchanged power;

- The insulation is considered in the model, it is covered by a metallic shield that is only considered in terms of surface emissivity and absorption;

- The air layer in the cavity is supposed to be stratified (Nusselt number is close to 1 and the heat transfer mainly occurs by conduction);

- Two spectral bands are considered: visible and IR;

- The solar irradiance on the insulation is considered as a heat source;

- Inertia is not considered;

- The model is one-dimensional. 
There is a total of six temperatures to be calculated: inner and outer temperatures of the tube, inner and outer temperatures of the insulation and inner and outer temperatures of the window. Six equations are required and are described in the following.

\section{Heat balance on the tubes:}

The power absorbed by the fluid (only the lower half of the absorber is assumed to participate to heat transfer since only the lower half of the tubes is irradiated) can be written as follows:

$\varphi 10=h_{f} \times\left(T_{t, i n}-T_{f}\right) \times\left(r-e_{t}\right) \times \pi \times n$

(the mean fluid temperature is considered)

The conduction through the tube wall (again, only the lower half of the tube is assumed to participate to heat transfer) gives:

$\varphi 2=\lambda_{t} / e_{t} \times\left(\frac{2 \times \pi \times e_{t}}{\ln \left(\frac{r}{r-e_{t}}\right)}\right) \times n / 2 \times\left(T_{t, \text { out }}-T_{t, \text { in }}\right)$

The solar power reaching the tube can be expressed as follows:

$\varphi 1=F s \times \tau_{\text {window }}^{\text {vis }} \times L_{v}$

The solar power reflected by the tubes is:

$\varphi 3=\varphi 1 \times \rho_{\text {tube }}^{\text {vis }}$

The exchanged power between the tubes and the window inner face is given by the conduction in the air layer:

$\varphi 4=\lambda_{\text {air }} / H \times\left(T_{t, \text { out }}-T_{\text {window,in }}\right) \times L_{v}$ 
The net power exchanged between the tubes and the window (according to Kirchhoff's law applied to grey body: $\alpha_{\text {tubes }}^{I R}=\varepsilon_{\text {tubes }}^{I R}$ ) is given by the following equation:

$\varphi 5=\frac{\sigma \times\left(T_{t, \text { out }}^{4}-T_{\text {window,in }}^{4}\right)}{1 / \varepsilon_{\text {tube }}^{I R}+\left(1 / \varepsilon_{\text {window }}^{I R}-1\right)} \times L_{v}$

The net power exchanged between the tubes and the insulation is given below:

$\varphi 11=\frac{\sigma \times\left(T_{t, \text { out }}^{4}-T_{\text {insulation, in }}^{4}\right)}{1 / \varepsilon_{\text {tube }}^{I R}+\left(1 / \varepsilon_{\text {ins }}^{I R}-1\right)} \times L_{v}$

The conduction between the tubes and the insulation through the air layer (convection is neglected due to the stable stratified layer of hot air in the top portion of the cavity (Pye, 2008)) is also included:

$\varphi 15=\lambda_{\text {air }} / h \times\left(T_{t, \text { out }}-T_{\text {insulation, in }}\right) \times L_{v}$

Finally, the balance gives:

$\varphi 1=\varphi 2+\varphi 3+\varphi 4+\varphi 5+\varphi 11+\varphi 15$

\section{Heat balance on the window:}

The incident solar power absorbed in the visible spectrum is calculated as follows:

$\varphi 7=\alpha_{\text {window }}^{\text {vis }} \times F S \times L_{v}$

The solar power reflected by the tubes and absorbed in the visible spectrum by the window leads to the following expression:

$\varphi 6=\alpha_{\text {window }}^{\text {vis }} \times \varphi 3$

The absorbed power in the IR spectrum equals $\varphi 5$.

The heat equation at the window can be written as: 
$\rho \times C \times \frac{\partial T}{\partial t}=\lambda_{w} \times \Delta T+\varphi$

with $\varphi$, the volumetric heat production due to the absorption of the window in the visible spectrum.

For steady state and one dimensional problem, it becomes:

$$
\Delta T=\frac{\partial^{2} T}{\partial x^{2}}=-\varphi / \lambda_{w}
$$

The boundary conditions are as follows:

$T_{x=0}=T_{\text {window }, \text { out }}$

$\lambda_{w} \times\left(\frac{\partial T}{\partial x}\right)_{x=0}=\left(h_{\text {ext }}+h_{\text {rad }}\right) \times\left(T_{\text {window }, \text { out }}-T_{0}\right)$

With

$h_{\text {rad }}=\varepsilon_{\text {window }}^{I R} \times \sigma \times\left(T_{\text {window, out }}^{2}+T_{0}^{2}\right) \times\left(T_{\text {window, out }}+T_{0}\right)$

After integration:

$T_{\text {window, in }}=-\frac{\dot{q} \times e_{w}}{2 \times \lambda_{w} \times L_{v}}+\frac{h_{\text {ext }}+h_{\text {rad }}}{\lambda_{w}} \times\left(T_{\text {window ,out }}-T_{0}\right) \times e_{w}+T_{\text {window ,out }}$

with $\dot{q}=\varphi 6+\varphi 7$

The convection losses are calculated as follows: 


$$
\varphi 8=h_{\text {ext }} \times\left(T_{\text {window, out }}-T_{0}\right) \times L_{v}
$$

The radiant heat losses are also taken into account:

$\varphi 9=\varepsilon_{\text {window }}^{I R} \times \sigma \times\left(T_{\text {window,out }}^{4}-T_{0}^{4}\right) \times L_{v}$

The balance on the window leads to:

$\varphi 7+\varphi 6+\varphi 5+\varphi 4=\varphi 8+\varphi 9$

\section{Heat balance on the insulation:}

The loss by convection is detailed below:

(the external surface is increased in order to take into account the side effects)

$$
\varphi 12=h_{\text {ext }} \times\left(T_{\text {insulation, out }}-T_{0}\right) \times\left[\left(L_{v}+2 \times e_{\text {ins }}\right)+2 \times(H+h+2 \times r)\right]
$$

The radiative loss by the insulation is given by:

$$
\varphi 13=\sigma \times \varepsilon_{\text {shield }} \times\left(T_{\text {insulation, out }}^{4}-T_{0}^{4}\right) \times\left[\left(L_{v}+2 \times e_{\text {ins }}\right)+2 \times(H+h+2 \times r)\right]
$$

The conduction in the insulation is expressed as follows:

$$
\varphi 14=\lambda_{\text {ins }} / e_{\text {ins }} \times\left(T_{\text {insulation, in }}-T_{\text {insulation, out }}\right) \times L_{v}
$$

Finally, the balance is (for the lower and upper insulation interfaces respectively):

$$
\varphi 14=\varphi 11+\varphi 15
$$

$\varphi 14+L_{v} \times S_{f} \times \alpha_{\text {shield }}=\varphi 12+\varphi 13$

This model gives access to a polynomial expression of the receiver efficiency as a function of the 
concentrated flux at the window (given by the optical model) and the fluid temperature (Kutscher, 2010; Desai et al., 2015). The polynomial equation has the following expression:

$\eta_{\text {receiver }}=\eta_{0}-\mathrm{a} 1 \times \frac{\left(\mathrm{T}_{\text {fluid }}-\mathrm{T}_{\text {ext }}\right)}{\mathrm{Fs}}-\mathrm{a} 2 \times \frac{\left(\mathrm{T}_{\text {fluid }}-\mathrm{T}_{\text {ext }}\right)^{2}}{\mathrm{Fs}}$

a1 and a2 are heat loss coefficients as defined by the EN 12975-2 (in $\mathrm{W} /\left(\mathrm{m}^{2} \times \mathrm{K}\right.$ ) and $\mathrm{W} /\left(\mathrm{m}^{2} \times \mathrm{K}^{2}\right)$ respectively)

With a quadratic temperature dependence and an exponent of 1 on the flux, the model fits the data with more than $1 \%$ accuracy over the temperature range $\left[100-300{ }^{\circ} \mathrm{C}\right]$ and the concentrated flux range $[5000-50000$ $\left.\mathrm{W} / \mathrm{m}^{2}\right]$.

From the optical model, the flux at the receiver window is estimated and, knowing the fluid temperature, one can calculate the receiver efficiency based on the polynomial fit. This simple model enables a quick simulation of the solar field thermal performances.

\subsection{Learned models}

While developing our tool, we observed recurrent differences in terms of level and shape between forecasts and measurements (both for DNI and power). Two models were designed to learn these differences and to correct our forecasts. The first one is dedicated to the re-estimation of the level of the forecast and another one for its shape. Each model is applied twice: once for DNI and once for power.

\subsubsection{Rescaling models (sc)}

The rescaling model is dedicated to the fine tuning of the forecasted total energy. This model is applied on two different types of data during the algorithm, leading to the two following cases.

In both cases, a daily energy $\mathrm{E}$ is considered. The difference between the two cases can be explained by the definition of the considered energy:

Case 1). A first rescaling model focuses on the received energy based on DNI (see Fig 2 "meteorological models" insert). In that case $E_{\text {measured }}$ and $E_{\text {forecasted }}$ are defined as 


$$
E_{\text {measured }}=\int_{\text {day }} D N I_{\text {measured }}(t) \times A \times d t
$$

and

$$
E_{\text {forecasted }}=\int_{d a y} D N I_{\text {Fnwp }}(t) \times A \times d t
$$

Case 2). The second rescaling model focuses on the thermal energy produced by the plant (Fig 2 "thermal and electrical models" insert). In that case $E_{\text {measured }}$ and $E_{\text {forecasted }}$ are defined as $E_{\text {measured }}=\int_{\text {day }} P_{\text {measured }}(t) \times d t$

and

$$
E_{\text {forecasted }}=\int_{\text {day }}\left(P(t) / D N I_{\text {measured }}(t)\right) \times d t
$$

where $\left(P(t) / D N I_{\text {measured }}(t)\right)$ is not a mathematical division but the power forecasted by the plant model when fed by measured DNI along the day (in learning model, this model is usually fed by forecasted DNI).

Each day, measured and forecasted energies are compared. For a given day $d$,

$$
\text { Coeff }_{d}=E_{\text {measured }} / E_{\text {forecasted }}
$$

The median of Coeff $_{i}$ over the last 30 days is used as correction coefficient for the current forecasts:

$$
M_{s c}=\underset{d \in S}{\operatorname{median}}\left(\text { Coeff }_{\text {day }}\right)
$$

where $S$ is the set of the previous 30 days.

Each day, the value of $M_{s c}$ is learned. If too few data are available to learn the $M_{s c}$ parameter, $M_{s c}$ is set to 1 .

Forecasts are thus improved by accounting for this coefficient: 


$$
P_{F s c}=M_{s c} \times P_{F t h}
$$

\subsubsection{Reshaping models (sh)}

The reshaping model is designed to correct the shape of the forecasted curves along the day. This model has to be applied (or learned) after the rescaling model. Similarly to the rescaling model, the reshaping model considers two different energy types corresponding to the two following cases. However, unlike the previous model for which the energy is considered on a daily basis, half-an-hour windows are preferred here.

Case 1). A first reshaping model focuses on the received energy based on DNI ("meteorological models" insert in Fig. 2). In that case $E_{F s c}(t)$ and $E_{\text {measured }}(t)$ are the energies based on DNI during the time step $\mathrm{t}$ (there are 48 half-an-hour time steps during a day).

Case 2). The second reshaping model focuses on the thermal energy produced by the plant ("thermal and electrical models" insert in Fig. 2). In that case $E_{F s c}(t)$ and $E_{\text {measured }}(t)$ are the energies based on the power foreseen by the plant model fed by $D N I_{F s c s h}$ and $D N I_{\text {measured }}$ respectively.

Then, ideal_correction ${ }_{d}(t)$ can be defined as the deformation that should be applied to the forecast to perfectly fit the shape of the curves during day $d$ :

ideal_correction $_{d}(t)=E_{F s c}(t) \times \frac{\sum_{i=1}^{48} E_{\text {measured }}(i)}{\sum_{i=1}^{48} E_{F s c}(i)}-E_{\text {measured }}(t)$

where ideal_correction ${ }_{d}(t)$ is a value related to day $d$ and time step $t . D N I_{\text {measured }}(t)$ is the actual average DNI measured at time step $t$.

It can be observed that the mean of ideal_correction ${ }_{d}$ during a given day $d$ equals 0 . This model is dedicated to the shape learning, whereas the daily energy learning falls in the scope of the rescaling model. 
The evaluation of the forecast deformation can benefit from the observation of several former ideal_correction $_{d}(t)$ curves. If some features often occur, they will probably impact the future measurements and forecasts should account for it. To do so, the last 30 daily curves of ideal_correction are considered. At each time step $t$, we can associate the previous 30 ideal_correction values.

We define:

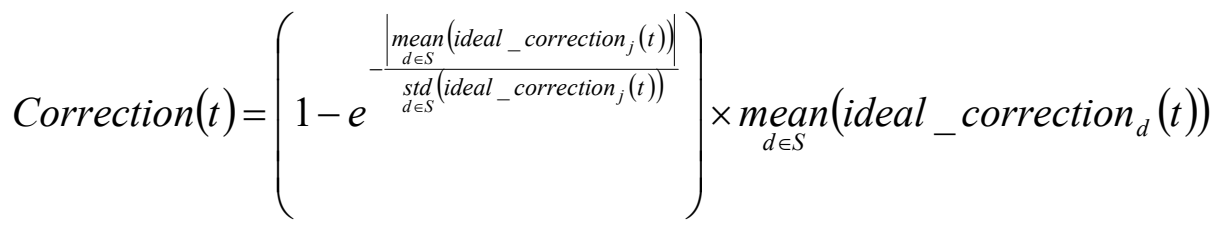

where $S$ is the set of the previous 30 days.

A zero padding of "Correction" can be implemented as long as a 30 days ideal_correction dataset is not available.

Forecasts are thus improved by accounting for this model:

$$
\begin{aligned}
& \text { Case } D N I_{F s c s h}=D N I_{F s c}-\operatorname{Correction}(t) \\
& \text { Case 2) } \quad P_{\text {forecasted }}=P_{F s c}-\operatorname{Correction}(t)
\end{aligned}
$$

\subsubsection{Special cases}

In the previous sections, we assume that DNI measurements are available at the plant. However, two "degraded modes" could be imagined if this assumption is not satisfied.

Case 1: There is no DNI measurement on the site, but Ghi measurements are available. In such a case, DNI may be estimated using the decomposition model (see section 3.2).

Case 2: There is no irradiance measurement on the site but power measurements are available. In such a case, rescaling and reshaping models are not learned in the "meteorological models" insert (see Fig.2). The rescaling and reshaping models in the "plant models" insert use the following inputs:

Rescaling model: 


$$
E_{\text {measured }}=\int_{\text {day }} P_{\text {measured }}(t) \times d t
$$

and

$$
E_{\text {forecasted }}=\int_{\text {day }} P_{\text {forecasted }}(t) \times d t
$$

Reshaping model: $E_{F s c}(t)$ and $E_{\text {measured }}(t)$ are the energies based on the power forecasted by the plant model fed by $D N I_{F s c s h}$ and $P_{\text {measured }}$ respectively.

\section{Evaluation procedures}

\subsection{Evaluation of the complete system}

Each author uses its own method to evaluate the accuracy of power plant production forecasts (Lespinats et al., 2011). The relative immaturity of this scientific field can explain the lack of agreed benchmarks. Nonetheless, the harmonization of model evaluation will suffer from the large variety of addressed issues. Indeed, the goals of the authors depend on the final use case (grid stability, energy management, etc...), on the geographical situation, on the local legislation, etc... and on their point of view about the future evolution of such a context. The choice of the method used in the present paper is based on the French rules for penalty calculation when a power plant fails to follow its production guideline.

It must be noticed that many authors use RMSE (Root Mean Square Error) rather than MAE (Mean Absolute Error) in comparable cases (Schroedter-Homscheidt and Pulvermüller, 2011; Lara-Fanego, 2012; Martin et al., 2010). The choice of RMSE is supported by its very good statistical features. However, MAE is preferred here because of its intuitive aspect. The MAE is closely linked to the mean difference measured in Wh (Watt $\times$ hours). Conversely, RMSE cannot be related to any well-known quantity. Moreover, it is sometimes recommended to prefer MAE to RMSE in similar context for theoretical reasons (Willmott and Matsuura, 2005). Obviously, the MAE can be calculated for persistence in the very same way as the MAE for our forecasting tool. The comparison between these two values allows evaluating our system.

Currently, datasets are collected in order to improve the models and to learn new parameters. For example, if 
thermal power is considered and $P_{\text {forecasted }}(k)$ is the averaged power forecasted during the half an hour window number $k$ (the windows are not self-recovering) belonging to day $d$ and $P_{\text {produced }}(k)$ is the averaged power produced during the same period then:

$M A E_{d a y}^{P}(d)$ is the mean absolute error for day $d$.

$M A E_{d a y}^{P}(d)=\frac{\sum_{\text {sunrise }}^{\text {sunset }}\left|P_{\text {forecasted }}(k)-P_{\text {produced }}(k)\right|}{N_{d} \times P_{\text {ref }}}$

where $N_{d}$ is the number of half an hour windows between sunrise and sunset of day $d$.

$P_{r e f}$ is the reference power (expected power for DNI of $1000 \mathrm{~W} / \mathrm{m}^{2}$, with an ambient temperature of $15^{\circ} \mathrm{C}$, the sun is assumed to be at zenith).

$M A E_{d a y}^{P}(d)$ is dimensionless; the error is expressed as a proportion of $P_{r e f}$ (which can be seen as a parameter that accounts for the "size" of the plant). Consequently, if one can estimate $P_{\text {ref }}$, $M A E_{d a y}^{P}(d) \times P_{r e f}$ will be the average error of the forecasting model in terms of Watt (W).

This definition for MAE is equivalent to the one used in the photovoltaic forecasting field (see (Pelland et al. 2011) for example).

\subsection{Evaluation of the meteorological forecast}

The previously described procedure allows evaluating the whole system, but we could be interested in evaluating the method steps separately. For that reason, we also define here:

$M A E_{d a y}^{D N I}(d)=\frac{\sum_{\text {sunrise }}^{\text {sunset }}\left|D N I_{F s c h t}(k)-D N I_{\text {measured }}(k)\right|}{N_{d}}$

where $D N I_{F s c s h}(k)$ is the averaged DNI forecasted on window number $k, D N I_{\text {measured }}(k)$ is the averaged 
DNI measured during the same period.

$M A E_{d a y}^{D N I}(d)$ evaluates the forecast of DNI during day $d$.

The bias of the forecasts can be defined as:

$$
\operatorname{Bias}_{\text {day }}^{D N I}(d)=\frac{\sum_{\text {sunrise }}^{\text {sunset }}\left(D N I_{F s c s h}(k)-D N I_{\text {measured }}(k)\right)}{N_{d}}
$$

Unlike $M A E_{d a y}^{P}(d)$ which is dimensionless, $M A E_{d a y}^{D N I}(d)$ is a simple average difference between irradiances and is then expressed in $\mathrm{W} / \mathrm{m}^{2}$ (so as $\operatorname{Bias}_{d a y}^{D N I}(d)$ ).

\subsection{Evaluation of the optical and thermal models}

As far as optical and thermal models are concerned, they are dissociated but no solar flux data on the receiver are available. Only the thermal power output is measured. Thus, it is not possible to evaluate these models separately. The global evaluation is performed by a comparison between experimental thermal output and estimated thermal output while the thermal model is fed with the measured DNI. A step forward would be to measure the flux map at the receiver window and this would permit to evaluate separately the optical efficiency and the receiver efficiency.

\subsection{Evaluation relatively to persistence}

$M A E^{i}$ is the mean absolute error for a given site.

$M A E^{i}=\frac{\sum_{d=1}^{D} M A E_{d a y}^{i}(d)}{D}$

where $D$ is the number of available days (exponent "i" can be replaced here by "P" or "DNI"). 
The $d-1$ persistence model to forecast production on day $d+1$ is chosen as reference system. To explain this choice, let us suppose that we want to use the day $d$ persistence. The forecast for day $d+1$ would need the whole day $d$ data (from sunrise to sunset). But considering the French electricity regulation rules, this forecast has to be provided before $4 \mathrm{pm}$ on day $d$ (before sunset), which cannot be done in time! So, day $d-1$ is considered. The improvement index is equal to:

$$
\text { improvement }^{i}=\frac{M A E^{i}}{M A E_{\text {persistence }}^{i}}
$$

\section{Forecasting results}

\subsection{DNI forecast}

We used our method to forecast the DNI in several sites. In Table 1, 2 and 3, forecasts are evaluated according to three criteria according to equations (44), (45) and (46). Note that the global irradiance in the sites "CAD" and "INES" is not measured on horizontal plane. The sensors are oriented toward the south and the tilt equals $35^{\circ}$ for CAD case, and the sensor is fixed on a tracker for INES case.

Table 1: MAE $\left(\mathrm{W} / \mathrm{m}^{2}\right)$ of DNI and Ghi forecasts at various steps of the algorithm for 3 sites. The first column displays the MAE reached with the complete algorithm, the second column displays MAE reached when forecasting the global irradiance, the third and fourth columns display respectively the DNI forecasting without applying any learning model and while the rescaling model is applied solely. The four last columns correspond to MAE evaluations while the DNI and Ghi forecasts are reached by persistence on day d-1 or day d-2.

\begin{tabular}{|c|c|c|c|c|c|c|c|c|}
\hline SITE & $\begin{array}{l}\mathrm{DNI}_{\mathrm{Fscsh}} \\
\text {-complet } \\
\text { algorithm- }\end{array}$ & Ghi & $\mathrm{DNI}_{\text {Fnwp }}$ & $\mathrm{DNI}_{\mathrm{Fsc}}$ & $\begin{array}{l}\text { Persistence } \\
\text { (DNI / d-2) } \\
\text {-reference- }\end{array}$ & $\begin{array}{l}\text { Persistence } \\
(\mathrm{DNI} / \mathrm{d}-1)\end{array}$ & $\begin{array}{l}\text { Persistence } \\
(\mathrm{G} / \mathrm{d}-2) \\
\text {-reference- }\end{array}$ & $\begin{array}{l}\text { Persistence } \\
(\mathrm{G} / \mathrm{d}-1)\end{array}$ \\
\hline $\mathrm{CAD}$ & 102.4 & 45.4 & 139.3 & 103.7 & 152.7 & 134 & 79.9 & 71 \\
\hline INES & 93.7 & 89.7 & 118.8 & 95 & 125.7 & 101.6 & 124.3 & 104 \\
\hline Spain & 103.8 & 38.9 & 130.1 & 109.7 & 128.4 & 108.2 & 58.4 & 54 \\
\hline
\end{tabular}


Table 2: Comparison of DNI and Ghi forecasts in terms of "Improvement" (in \% of $\mathrm{MAE}^{\mathrm{DNI}}$ (persistence d-2) or $\mathrm{MAE}^{\mathrm{G}}$ (persistence d-2) respectively). Negative values mean that forecasts are less efficient than $d-2$ persistence. The same variables as in Table 1 are studied but with regards to Equation (46) criterion.

\begin{tabular}{|c|c|c|c|c|c|c|}
\hline SITE & $\begin{array}{l}\mathrm{DNI}_{\mathrm{Fscsh}} \\
\text {-complet } \\
\text { algorithm- }\end{array}$ & Ghi & $\mathrm{DNI}_{\text {Fnwp }}$ & $\mathrm{DNI}_{\mathrm{Fsc}}$ & $\begin{array}{l}\text { Persistence } \\
\text { (DNI / d-1) }\end{array}$ & $\begin{array}{l}\text { Persistence } \\
(\mathrm{G} / \mathrm{d}-1)\end{array}$ \\
\hline CAD & $32.94 \%$ & $43.18 \%$ & $8.78 \%$ & $32.09 \%$ & $12.25 \%$ & $11.14 \%$ \\
\hline INES & $25.46 \%$ & $27.84 \%$ & $5.49 \%$ & $24.42 \%$ & $19.17 \%$ & $16.33 \%$ \\
\hline Spain & $19.16 \%$ & $33.39 \%$ & $-1.32 \%$ & $14.56 \%$ & $15.73 \%$ & $7.53 \%$ \\
\hline
\end{tabular}

Table 3: Comparison of DNI and Ghi forecasts in terms of bias (average (forecast - measurements)) in $\mathrm{W} / \mathbf{m}^{2}$. The same variables as in Table 1 are studied but with regards to Equation (44) criterion.

\begin{tabular}{|c|c|c|c|c|c|c|c|c|}
\hline SITE & $\begin{array}{l}\mathrm{DNI}_{\text {Fscsh }} \\
\text {-complet } \\
\text { algorithm- }\end{array}$ & Ghi & $\mathrm{DNI}_{\text {Fnwp }}$ & $\mathrm{DNI}_{\mathrm{Fsc}}$ & $\begin{array}{l}\text { Persistence } \\
\text { (DNI / d-2) }\end{array}$ & $\begin{array}{l}\text { Persistence } \\
\text { (DNI / d-1) }\end{array}$ & $\begin{array}{l}\text { Persistence } \\
(\mathrm{G} / \mathrm{d}-2)\end{array}$ & $\begin{array}{l}\text { Persistence } \\
(\mathrm{G} / \mathrm{d}-1)\end{array}$ \\
\hline CAD & -1 & 20.7 & -86.2 & -2.9 & -2.6 & -1.9 & -0.7 & -0.8 \\
\hline INES & -44.8 & 41.3 & -104 & -45.1 & -1.1 & -4.5 & 1.4 & -36.9 \\
\hline Spain & -22.4 & 0.8 & -98.2 & -24.9 & -4.2 & -4.3 & -0.9 & 1.8 \\
\hline
\end{tabular}

\subsubsection{Comments on the results obtained on a particular case: the complete model in Cadarache}

We can observe in Table 1 that the error reached by our DNI forecasting equals $102.4 \mathrm{~W} / \mathrm{m}^{2}$ in terms of MAE in Cadarache site. This value corresponds to the average absolute error of our forecasts during diurnal time (considered time step of $30 \mathrm{~min}$ ). By comparison, the error reached by d-2 persistence in same conditions is $152.7 \mathrm{~W} / \mathrm{m}^{2}$. As a consequence, the improvement of the forecast relatively to d-2 persistence error equals $32.94 \%$ (see Table 2). The bias values of various forecasts are shown in Table 3. For example, the bias of our forecasts in Cadarache is about $1 \mathrm{~W} / \mathrm{m}^{2}$ (the value in Table 3 is negative meaning that on 
average our forecasts are $1 \mathrm{~W} / \mathrm{m}^{2}$ higher that real measurements). Similar values for Ghi can also be found in Tables 1, 2 and 3 for comparison.

\subsubsection{Analysis of various cases}

Globally, we can conclude from Table 1 and 2 that our forecasts are much closer to real measurements than the persistence model on the three sites. In terms of MAE, considering DNI solely, the rescaling model (section 3.3.1) is more critical than the reshaping model (section 3.3.2). However, the reshaping model allows improving results in all cases. The gains are more or less obvious, probably depending on the specific features of each site (tracking system, shading masks, local climate, number of available measurements, etc...). One can notice that the number of available days is of primary importance. The more available data we have, the longer the time usable for the learning procedure is. It is then expected that the efficiency of forecast increases with time, especially during the first month.

We may also notice that forecasting DNI is more difficult than forecasting Ghi. We assume that at least two different reasons may be involved:

1) Forecasting DNI calls an additional step (the radiation decomposition, see section 3.1) that increases uncertainty.

2) DNI is more variable than Ghi. On the one hand, the DNI measurement is less smooth than the Ghi curve. On the other hand, Ghi forecasts from NWP are smooth because their temporal resolution is weak (one single value each 3 hours, see section 2.3); derived DNI forecasts are smooth as well. The impact of high speed variability is then larger on DNI forecast.

Table 3 shows that the bias of our system is quite low, even if it is higher than the one of persistence (obviously, the bias of persistence tends to 0 when the number of available days increases). Here again, the rescaling model is critical.

\subsubsection{Exhibition of several typical forecasts}

The effect of the learning procedure is also illustrated in Fig. 6. The actual measurements are compared to the forecasts (given by the model including learning procedure, the model without learning and the persistence model); the expected value under clear sky hypothesis is also shown. Figs. 7 and 8 show the DNI 
forecast in Cadarache for two chosen days. The first forecast is made 48 hours before the beginning of the considered day. Then, the forecast is re-evaluated each six hours (curves become darker with the decrease of the temporal horizon). In Fig. 7 (July, 12 $2^{\text {th }}$ 2012), the weather is sunny. Obviously, a clear day is expected 2 days ahead and the forecasts remain stable while the time horizon decreases. Fig. 8 (June, 10 $\left.{ }^{\text {th }} 2012\right)$ shows a much more difficult case for which the weather is unstable: the day is sunny in the morning, but very cloudy in the afternoon. In this case, the forecasts are deeply modified (and improved) by the decrease of the temporal horizon. The last forecasts (darkest curves), which correspond to the forecasts for the current day, are pretty close to on-site measurements.

\subsection{Thermal power forecast}

Fig. 9 compares simulated and experimental results obtained on July, $12^{\text {th }} 2012$. About $15 \%$ deviation is obtained between experimental and simulated performances (based on real DNI measurements). This deviation can be explained by some of the assumptions made on the thermal model (one-dimensional model, cleanliness (mirrors, window), thermal losses neglected in pipes, thermal inertia...). Nevertheless, the objective is to keep a model as simple as possible and to forecast the real performances by adjusting the model on a large number of experiments thanks to learning procedures. Oscillations of the thermal power in Fig. 9 are in fact due to the shadow of the receiver on the mirrors: when the shadow is exactly on the mirror, the thermal power is less than when the shadow is between two mirrors. This phenomenon is not visible with the model since the optical discretization is too large, but this proves a good quality of the metrologic system. At the beginning of the day, the gap between the predicted and the experimental thermal powers comes from the start-up of the plant that requires thermal power to heat all the components (fluid, tubes...) and that is not usable.

\subsection{Coupling of DNI forecast and Fresnel performance model}

In Fig. 10, a validation example is described. The forecasted DNI (see section 5.1) can be fed into the Fresnel performance model (section 5.2) to forecast the thermal output. This complete forecasting chain can play a crucial role in the control strategy of the storage and the turbine (nominal, off-design), maximizing the profitability of the plant. In our test case, the thermal output is forecasted 24 hours in advance with less than 
$15 \%$ error during operation hours between $10 \mathrm{~h}$ and $18 \mathrm{~h}$. The gap between forecasted thermal output and experimental power is mainly due to the hypotheses on the Fresnel performance model (see Fig.9) that could be improved by an additional learning step (see section 4). The thermal model can also be refined to increase the final model accuracy. Indeed, it can be noticed that the DNI forecast is pretty well estimated, even if DNI is slightly underestimated. This DNI underestimation finally brings to a better agreement between the estimated thermal output and the experimental data; this is due to the fact that the thermal model tends to overestimate the output, so when it is fed with underestimated DNI, the errors tend to cancel each other out. Since the thermal model is restricted to one single dimension, the side effects are neglected and thus the thermal output is overestimated. In order to estimate a day ahead production, the model has also to take into account operating constrains (minimum acceptable load, start-up duration of the plant and of the storage). Before being applied for systematic thermal output forecast, these elements have to be taken into account. Nevertheless, an insight of what can be studied is shortly discussed in the next and last section.

\section{Optimized operating strategy perspectives}

Knowing the predicted DNI, it is possible to predict the thermal output of the plant. Optimization of the usable heat is thus made possible. According to the demand profile, the electricity price and the storage capacity, it will be possible to determine the most profitable strategy. The external temperature will be of importance since in the case of air cooled condensers, the efficiency of the power cycle is greatly improved when the external temperature decreases. In Fig. 11, a brief analysis shows that decreasing the cold temperature is even more beneficial than increasing the hot temperature for a Carnot cycle. For a hot temperature of $300{ }^{\circ} \mathrm{C}$ and a cold temperature of $50{ }^{\circ} \mathrm{C}$, increasing the hot temperature by $40{ }^{\circ} \mathrm{C}$ leads to a 8 $\%$ increase of the Carnot efficiency, whereas a $40{ }^{\circ} \mathrm{C}$ decrease of the cold temperature leads to a $16 \%$ increase in Carnot efficiency which is twice as much profitable. For example, from an energy point of view, it makes sense to direct the stored thermal energy to the turbine only late in the night when the external temperature is at its minimum; nevertheless, from an economic point of view, peak prices are in the evening. Depending on the feed-in tariff, various strategies emerge. Moreover, the strategy can be chosen according to the cooling capacity of the power block condenser that may be saturated during hot hours, which is a main constraint of CSP power plants. A software integrating all these aspects is currently under development and will enable to choose the best strategy based on the coupling of the meteorological prediction and the thermal performance model that are widely discussed in this paper. 


\section{Conclusion and outlook}

A model combining meteorological forecasts and thermal performances of a concentrating solar system is presented. Its outputs are compared to real experimental data obtained on a Fresnel prototype. By feeding the model with forecasted DNI, the power output of the plant can be estimated. In order to keep the number of input variables as low as possible, simple models are implemented and are improved by learning procedures. The future work will be to test various strategies and control systems in order to master all the components of a solar power plant and their interdependencies. Heat can be stored and thus gives to concentrated solar energy an additional dispatchability value. Our goal is to help operators to choose the optimal operation strategy knowing in advance the expected performances for each configuration. The forecasting tool can also be used as a performance diagnostic tool. Indeed, once validated, it can highlight abnormal discrepancies between expected and real performances and thus underline possible failures.

\section{Acknowledgements}

The authors would like to thank the INSTITUT CARNOT - Energie du Futur for its financial support.

\section{Nomenclature}

A

Mirror surface $\left(\mathrm{m}^{2}\right)$

$\mathrm{C}$

Heat capacity $(\mathrm{J} /(\mathrm{kg} \times \mathrm{K}))$

d

Index for a day

$\mathrm{D}$

Diffuse irradiance $\left(\mathrm{W} / \mathrm{m}^{2}\right)$

DNI

Direct Normal Irradiance $\left(\mathrm{W} / \mathrm{m}^{2}\right)$

$D N I_{\text {Fnwp }} \quad$ Direct Normal Irradiance forecast after decomposition of Ghi forecasts provided by GFS $\operatorname{model}\left(\mathrm{W} / \mathrm{m}^{2}\right)$

$D N I_{F s c} \quad$ Rescaled DNI forecast $\left(\mathrm{W} / \mathrm{m}^{2}\right)$ 


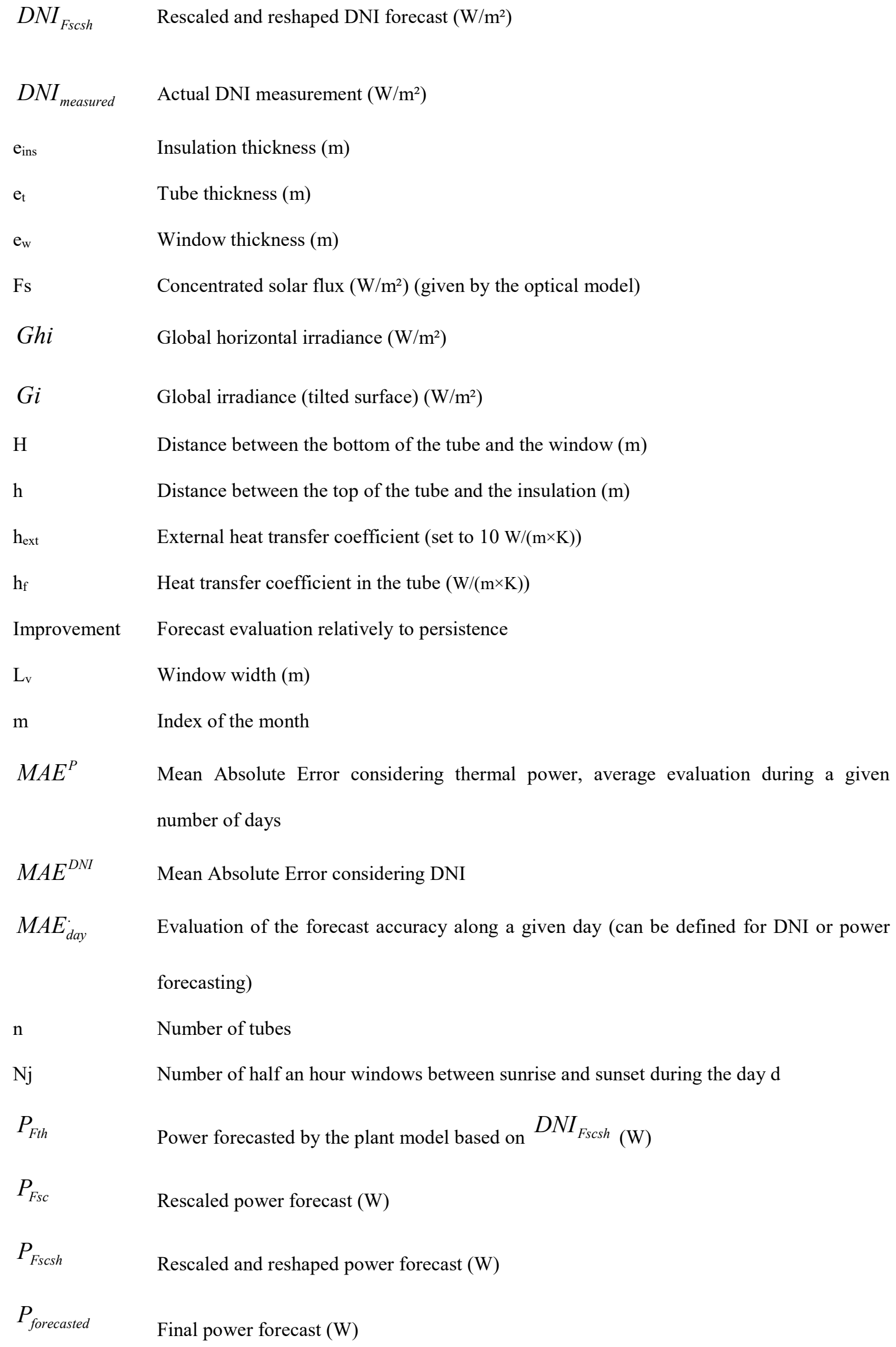




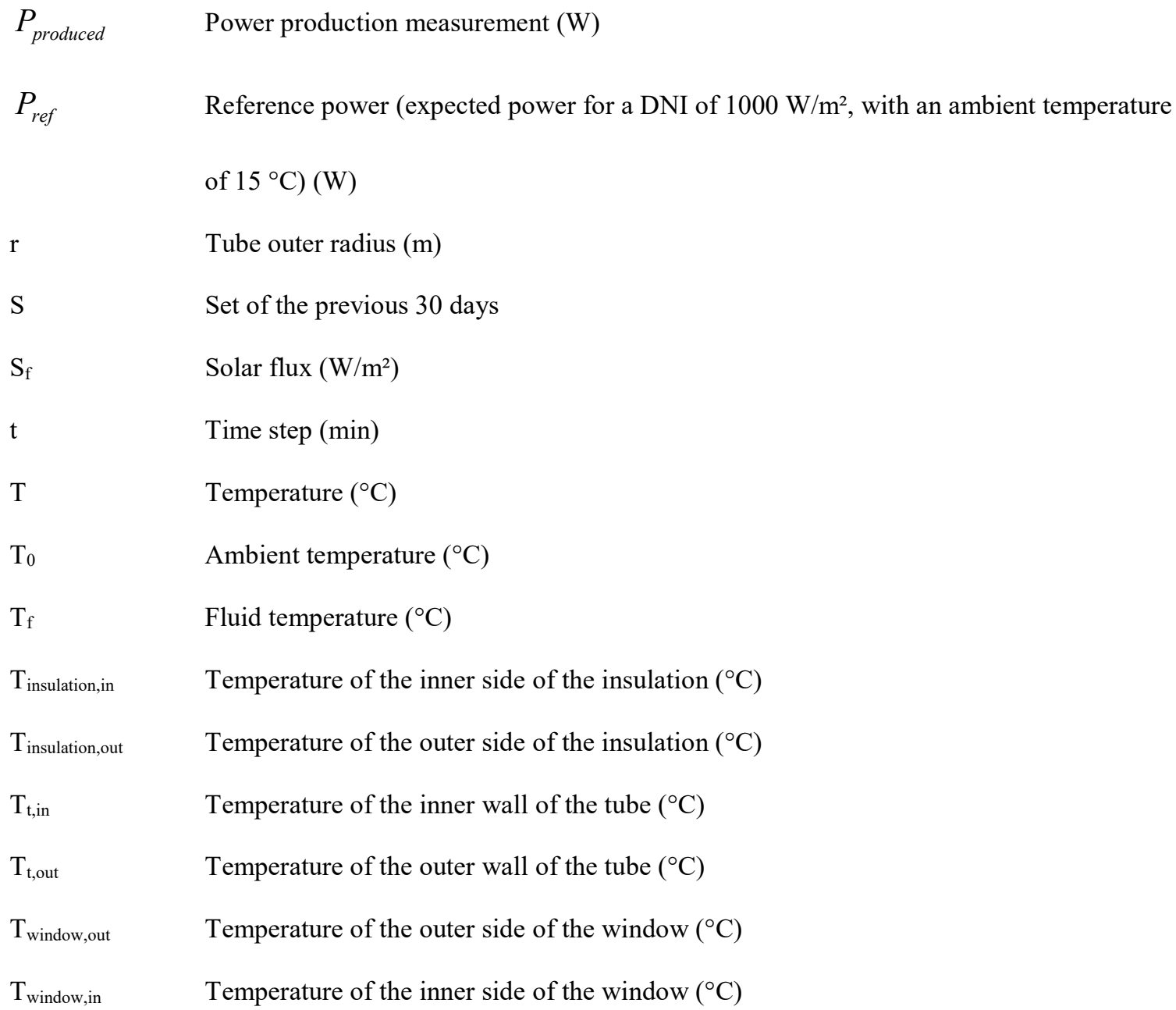

Greek letters:

$\begin{array}{ll}\alpha_{\text {shield }} & \text { Absorption coefficient of the shield in the visible spectrum } \\ \alpha_{\text {tubes }}^{I R} & \text { Absorption coefficient of the tubes in the IR spectrum } \\ \alpha_{\text {tubes }}^{\text {vis }} & \text { Absorption coefficient of the tubes in the visible spectrum } \\ \alpha_{\text {window }}^{I R} & \text { Absorption coefficient of the window in the IR spectrum } \\ \alpha_{\text {window }}^{\text {vis }} & \text { Emissivity of the shield in the IR spectrum } \\ \varepsilon_{\text {shield }} & \text { Emissivity of the insulation in the IR spectrum } \\ \varepsilon_{\text {ins }}^{I R} & \end{array}$




\begin{tabular}{|c|c|}
\hline$\varepsilon_{\text {tubes }}^{I R}$ & Emissivity of the tubes in the IR spectrum \\
\hline$\varepsilon_{\text {window }}^{I R}$ & Emissivity of the window in the IR spectrum \\
\hline$\lambda_{\text {air }}$ & Air thermal conductivity $(\mathrm{W} /(\mathrm{m} \times \mathrm{K}))$ \\
\hline$\lambda_{\text {ins }}$ & Insulation thermal conductivity $(\mathrm{W} /(\mathrm{m} \times \mathrm{K}))$ \\
\hline$\lambda_{\mathrm{t}}$ & Tube thermal conductivity $(\mathrm{W} /(\mathrm{m} \times \mathrm{K}))$ \\
\hline$\lambda_{\mathrm{w}}$ & Window thermal conductivity $(\mathrm{W} /(\mathrm{m} \times \mathrm{K}))$ \\
\hline$\rho_{\text {tubes }}^{I R}$ & Tube reflectivity in the IR spectrum \\
\hline$\rho_{\text {tubes }}^{\text {vis }}$ & Tube reflectivity in the visible spectrum \\
\hline$\rho_{\text {window }}^{I R}$ & Window reflectivity in the IR spectrum \\
\hline$\rho_{\text {window }}^{\text {vis }}$ & Window reflectivity in the visible spectrum \\
\hline$\sigma$ & Stefan Boltzman constant $\left(5.67 \times 10^{-8} \mathrm{~W} /\left(\mathrm{m}^{2} \times \mathrm{K}^{4}\right)\right)$ \\
\hline$\tau_{\text {window }}^{I R}$ & Window transmissivity in the IR spectrum \\
\hline$\tau_{\text {window }}^{\text {vis }}$ & Window transmissivity in the visible spectrum \\
\hline$\varphi$ & Volumetric heat production due to the absorption of the window in the visible spectrum \\
\hline & $\left(\mathrm{W} / \mathrm{m}^{3}\right)$ \\
\hline$\varphi \mathrm{i}$ & Linear flux (W/m) \\
\hline
\end{tabular}

\section{References}

Alliotte R., 2011. Superheated direct steam generation: alternative configuration for CLFR solar plants, Solarpaces Granada (Spain).

Al-Soud, M.S., Hrayshat E.S.. A 50MW concentrating solar power plant for Jordan, Journal of Cleaner Production, 17(6), 2009, 625-635. 
Bacher P., Madsen H., Nielsen H.A., 2009. Online short-term solar power forecasting, Solar Energy, 83(10), $1772-1783$

Breitkreuz H., Schroedter-Homscheidt M., Holzer-Popp T., Dech S., 2009. Short-range direct and diffuse irradiance forecasts for solar energy applications based on aerosol chemical transport and numerical weather modeling. J. Appl. Meteorol. Climatol. 48, 1766-1779.

Bruch A., Fourmigué J.F., Couturier R., 2012. Experimental Investigation of a Thermal Oil Dual-Media Thermocline for CSP Power Plant, Solarpaces, Marrakech (Morocco).

Dazhi Y., Jirutitijaroen P., Walsh W.M., 2012. Hourly solar irradiance time series forecasting using cloud cover index, Solar Energy, 86, 3531-3543.

Dervishi, S., \& Mahdavi, A. 2012. Computing diffuse fraction of global horizontal solar radiation: A model comparison. Solar Energy, 86(6), 1796-1802.

Desai, N.B., Bandyopadhyay S.. Optimization of concentrating solar thermal power plant based on parabolic trough collector, Journal of Cleaner Production, 89, 2015, 262-271.

Erbs, D. G., Klein, S. A., \& Duffie, J. A. 1982. Estimation of the diffuse radiation fraction for hourly, daily and monthly-average global radiation. Solar energy, 28(4), 293-302.

Espinar, B., Aznarte, J. L., Girard, R., Moussa, A. M., \& Kariniotakis , G. (2010). Photovoltaic Forecasting: A state of the art. In Proceedings 5th European PV-Hybrid and Mini-Grid Conference.Forristall R., 2003. Heat Transfer Analysis and Modeling of a Parabolic Trough Solar Receiver Implemented in Engineering Equation Solver, NREL/TP-550-34169, 1-145.

Forristall R., 2003. Heat Transfer Analysis and Modeling of a Parabolic Trough Solar Receiver Implemented in Engineering Equation Solver, NREL/TP-550-34169, 1-145.

Francia G., 1968. Pilot Plants of Solar Steam Generation Systems, Solar Energy, 12, 51-64.

Garcia I.L., Alvarez J.L., Blanco D., 2011. Performance model for parabolic trough solar thermal power plants with thermal storage: Comparison to operating plant data, Solar Energy, 85, 2443-2460.

Giostri A., Binotti M., Astolfi M., Silva P., Macchi E., Manzolini G., 2012. Comparison of different solar plants based on parabolic trough technology, Solar Energy, 86, 1208-1221. 
Hagedorn R., Hamill T.M., Whitaker J.S., 2008. Probabilistic forecast calibration using ECMWF and GFS ensemble reforecasts. Part I: Two-meter temperatures. Monthly Weather Review, 136(7).

Hammer A., Heinemann D., Hoyer C., Kuhlemann R, Lorenz E., Müller R., Beyer H.G., 2003. Solar Energy Assessment Using Remote Sensing Technologies. Remote Sensing of Environment, 86, 423-432.

Hansen C., Stein J., Gerstmaier T., Buhrer M., Rottger M., Gombert A., 2012. How predictable is DNI? An evaluation of hour ahead and day ahead DNI forecasts from four different providers (No. SAND20123465C). Sandia National Laboratories.

Heinemann D., Lorenz E., Girodo M., 2006. Forecasting of solar radiation E.D. Dunlop, L. Wald, M. Š́ri (Eds.), Solar Energy Resource Management for Electricity Generation from Local Level to Global Scale, NovaScience Publishers, Hauppauge.

Ho C.K., Software and Codes for Analysis of Concentrating Solar Power Technologies, 2008, SANDIA Report SAND2008-8053, 1-35.

Kutscher C., Burkholder F., Stynes K., 2010. Generation of a Parabolic Trough Collector Efficiency Curve from Separate Measurements of Outdoor Optical Efficiency and Indoor Receiver Heat Loss, Solarpaces, Perpignan (France).

Kovacs P. A guide to the standard EN 12975, 2012, available online: http://www.estif.org/fileadmin/estif/content/projects/QAiST/QAiST_results/QAiST\%20D2.3\%20Guide\% 20to\%20EN\%2012975.pdf

Lara-Fanego V., Ruiz-Arias J.A., Pozo-Vàzquez D., Santos-Alamillos F.J., Tovar-Pescador J., 2012. Evaluation of the WRF model solar irradiance forecasts in Andalusia (southern Spain), Solar Energy, 86, 2200-2217.

Law, E. W., Prasad, A. A., Kay, M., \& Taylor, R. A. 2014. Direct normal irradiance forecasting and its application to concentrated solar thermal output forecasting-A review. Solar Energy, 108, 287-307.

Lespinats S., Cugnet F., Guillou H., Le Pivert X., 2011. How much PV energy will I produce tomorrow? A forecasting tool which fits the future conditions on the French electricity market. Proceedings of 24th European Photovoltaic and Solar Energy Conference and Exhibition Hamburg (Germany).

Lespinats, S., Stoops, G., Pistarino, T., Le Pivert, X. 2014. "Forecasting the solar production from a plurality of sources." 29th European Photovoltaic Solar Energy Conference and Exhibition, PV SEC, 5AO.8.6. 
Amsterdam, Netherlands.

Lin, K.P., Pai, P.F., 2015. Solar power output forecasting using evolutionary seasonal decomposition leastsquare support vector regression. Journal of Cleaner Production in press.

Lorenz E., Scheidsteger T., Hurka J., Heinemann D., Kurz C., 2011. Regional PV power prediction for improved grid integration, Progress in Photovoltaics: Research and Applications. 19(7), 757-771.

Manzolini G., Giostri A., Saccilotto C., Silva P., Macchi E., 2011a. Development of an innovative code for the design of thermodynamic solar power plants part A: Code description and test case, Renewable Energy, 36, 1993-2003.

Manzolini G., Giostri A., Saccilotto C., Silva P., Macchi E., 2011b. Development of an innovative code for the design of thermodynamic solar power plants part B: Performance assessment of commercial and innovative technologies, Renewable Energy, 36(9), 2465-2473.

Marquez R., Coimbra C.F.M., 2011. Forecasting of global and direct solar irradiance using stochastic learning methods, ground experiments and the NWS database, Solar Energy, 85, 746-756.

Marquez R., Pedro H.T.C., Coimbra C.F.M, 2013a. Hybrid solar forecasting method uses satellite imaging and ground telemetry as inputs to ANNs. Solar Energy, 92, 176-188.

Marquez R., Coimbra C.F.M. 2013b. Intra-hour DNI forecasting based on cloud tracking image analysis, Solar Energy, 91, 327-336.

Martin L., Zarzalejo L.F., Polo J., Navarro A., Marchante R., Cony M., 2010. Prediction of global solar irradiance based on time series analysis: application to solar thermal power plants energy production planning. Solar Energy 84 (10), 1772-1781.

Mellit, A., 2008. Artificial intelligence techniques for modelling and forecasting of solar radiation data: A review. International Journal of Artificial Intelligence and Soft Computing 1, 52-76.

Mellit A., Eleuch H., Benghanem M., Elaoun C., Pavan A.M., 2010. An adaptive model for predicting of global, direct and diffuse hourly solar irradiance. Energy Conversion and Management, 51(4), 771-782.

Morin G., Dersch J., Platzer W., Eck M., Häberle A., Comparison of Linear Fresnel and Parabolic Trough Collector power plants, Solar Energy, 86, 2012, 1-12.

Muñoz J., Martínez-Val J.M., Abbas R., Abánades A., 2012. Dry cooling with night cool storage to enhance solar power plants performance in extreme conditions áreas, Applied Energy, 92, 429-436. 
Nixon, J.D., Dey P.K., Davies P. A., Design of a novel solar thermal collector using a multi-criteria decisionmaking methodology, Journal of cleaner production, 59, 2013, 150-159.

Pelland S., Galanis G., Kallos G., 2011. Solar and photovoltaic forecasting through post-processing of the Global Environmental Multiscale numerical weather prediction model. Prog. Photovolt: Res. Appl.

Powell K.M., Edgar T.F., 2012. Modeling and control of a solar themal power plant with thermal energy storage, Chemical Engineering Science, 71, 138-145.

Pye J.D., System Modelling of the Compact Linear Fresnel Reflector, 2008, University of New South Wales thesis.

Qazi, A., Fayaz, H., Wadi, A., Raj, R.G., Rahim, N.A., Khan, W.A., 2015. The artificial neural network for solar radiation prediction and designing solar systems: a systematic literature review. Journal of Cleaner Production 104, 1-12.

Remund J. and Müller. S.C. (2012) "Solar forecast survey results” 27th European Photovoltaic Solar Energy Conference and Exhibition, PV SEC, 5AV.2.29. sept 2012.

Romeo G.M., Ramírez L., Fernandes P.M., Lozano S., Nicuesa X., Pagola I., 2011. A system of direct radiation forecasting based on numerical weather predictions satellite image and machine learning. ISF International Symposium on Forecasting, Prague.

Ruiz-Arias J.A., Pozo-Vázquez D., Lara-Fanego V., Santos-Alamillos F.J., Tovar-Pescador J., 2011. A HighResolution Topographic Correction Method for Clear-Sky Solar Irradiance Derived with a Numerical Weather Prediction Model, Journal of Applied Meteorology \& Climatology, 50(12).

Sáez-Martínez, F.J., Mondéjar-Jiménez, J., Mondéjar-Jiménez, J.A. 2015. The energy challenge: energy and Environment Knowledge Week E2KW 2013 - Journal of Cleaner Production, 86, 471-473.

Schroedter-Homscheidt M., Pulvermüller B., 2011.Verification of direct normal irradiance forecasts for the concentrating solar thermal power plant Andasol-3 location, Solarpaces, Grenada (Spain).

Selig M., 2011. Commercial CSP plants based on Fresnel collector technology, Solarpaces, Granada (Spain).

Singh P.L., Sarviya R.M., Bhagoria J.L., 2010. Heat loss study of trapezoidal cavity absorbers for linear solar concentrating collector, Energy Conversion and Management, 51, 329-337.

Suri M., Remund J., Cebecauer T., Hoyer-Klick C., Dumortier D., Huld T., Stackhouse P.W.Jr, Ineichen P., 2009. Comparison of Direct Normal Irradiation Maps for Europe, Solarpaces, Berlin (Germany). 
Taylor A.A., Leslie L.M., 2005. A single-station approach to model output statistics temperature forecast error assessment. Weather \& Forecasting, 20(6).

Willmott C. J., Matsuura K., 2005. Advantages of the mean absolute error (MAE) over the root mean square error (RMSE) in assessing average model performance, Climate Research, 30(1), 79-82.

Yang, D., Dong, Z., Nobre, A., Khoo, Y. S., Jirutitijaroen, P., \& Walsh, W. M. 2013. Evaluation of transposition and decomposition models for converting global solar irradiance from tilted surface to horizontal in tropical regions. Solar Energy, 97, 369-387.

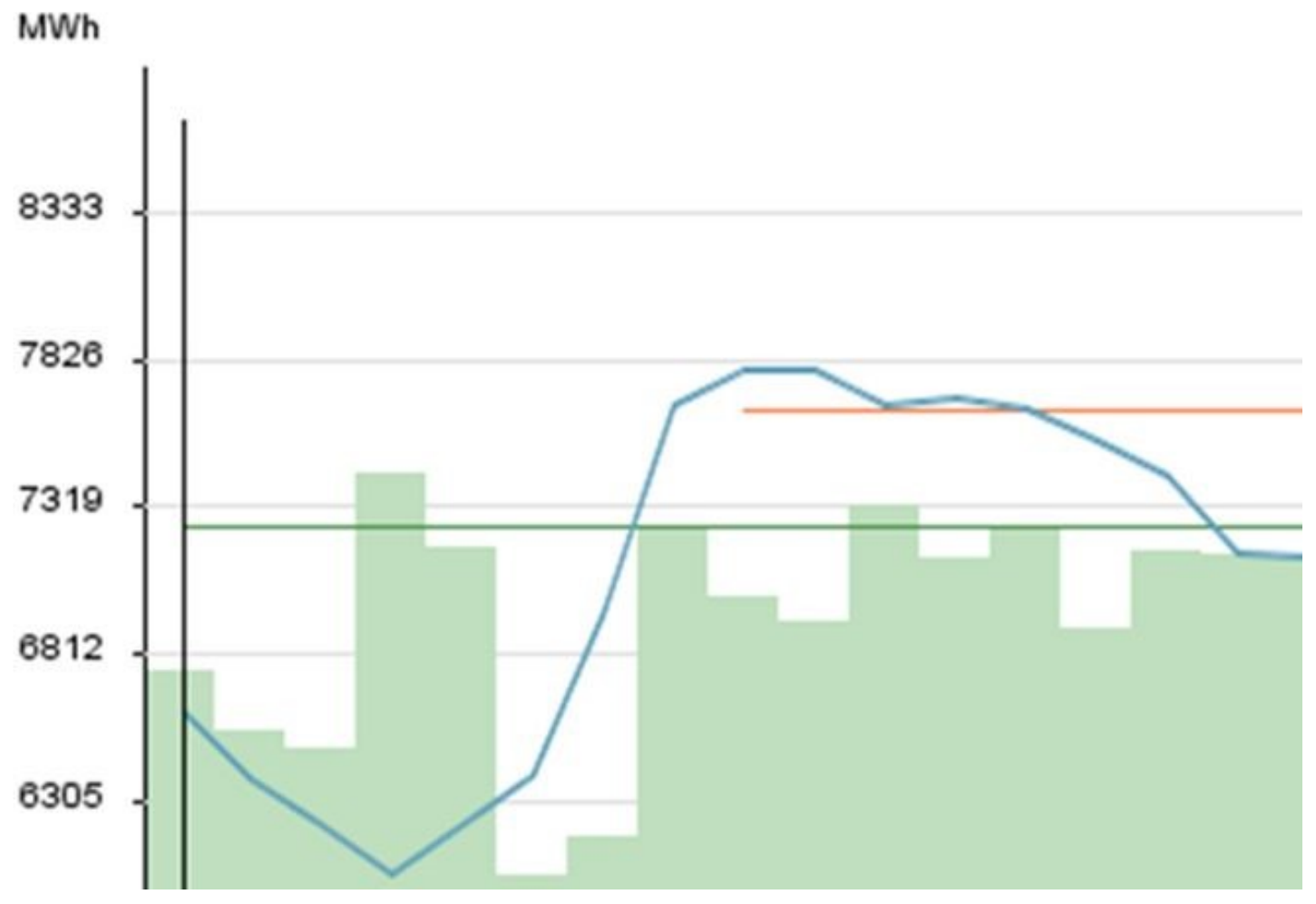

Fig. 1. Hourly prices and volumes of Epex Spot for the delivery day of 10 February 2012 


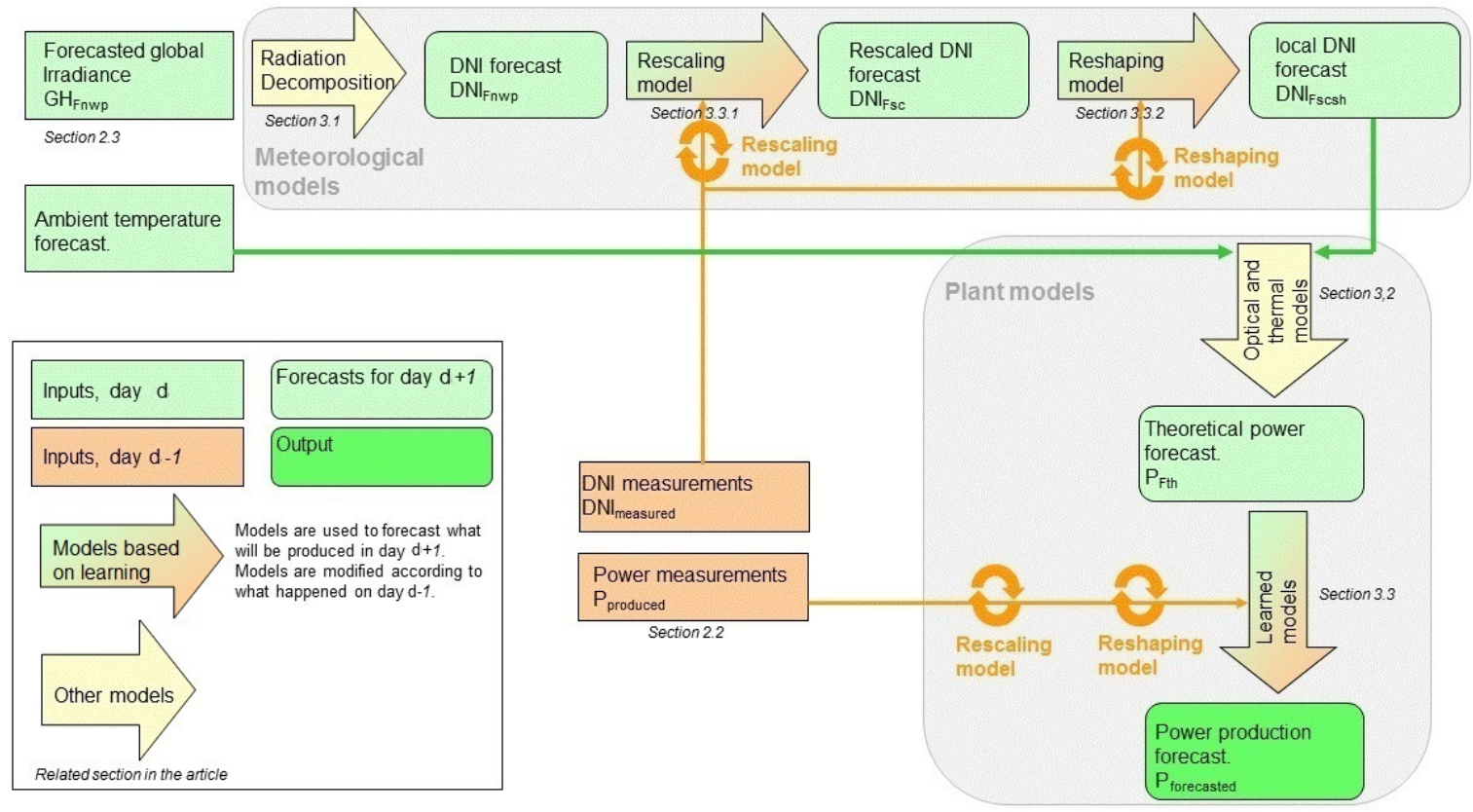

Fig. 2. Functional diagram of the forecasting tool

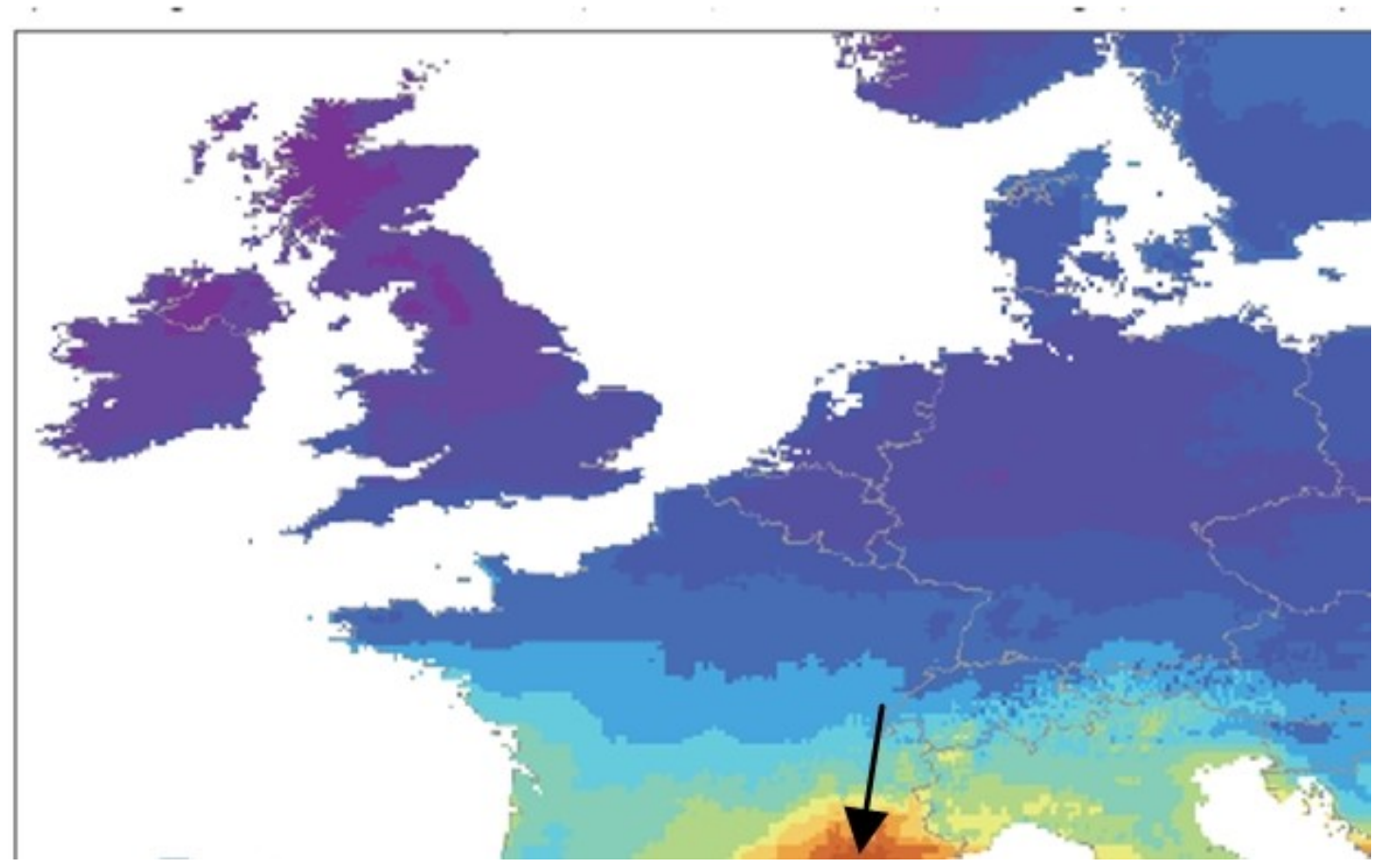

Fig. 3. Yearly sum of Direct Normal Irradiance - average of five databases: Meteonorm, PVGIS,

NASA SSE, Satel-Light, and SOLEMI $\left[\mathrm{kWh} / \mathrm{m}^{2}\right]$. (The arrow points out the solar plant location) 


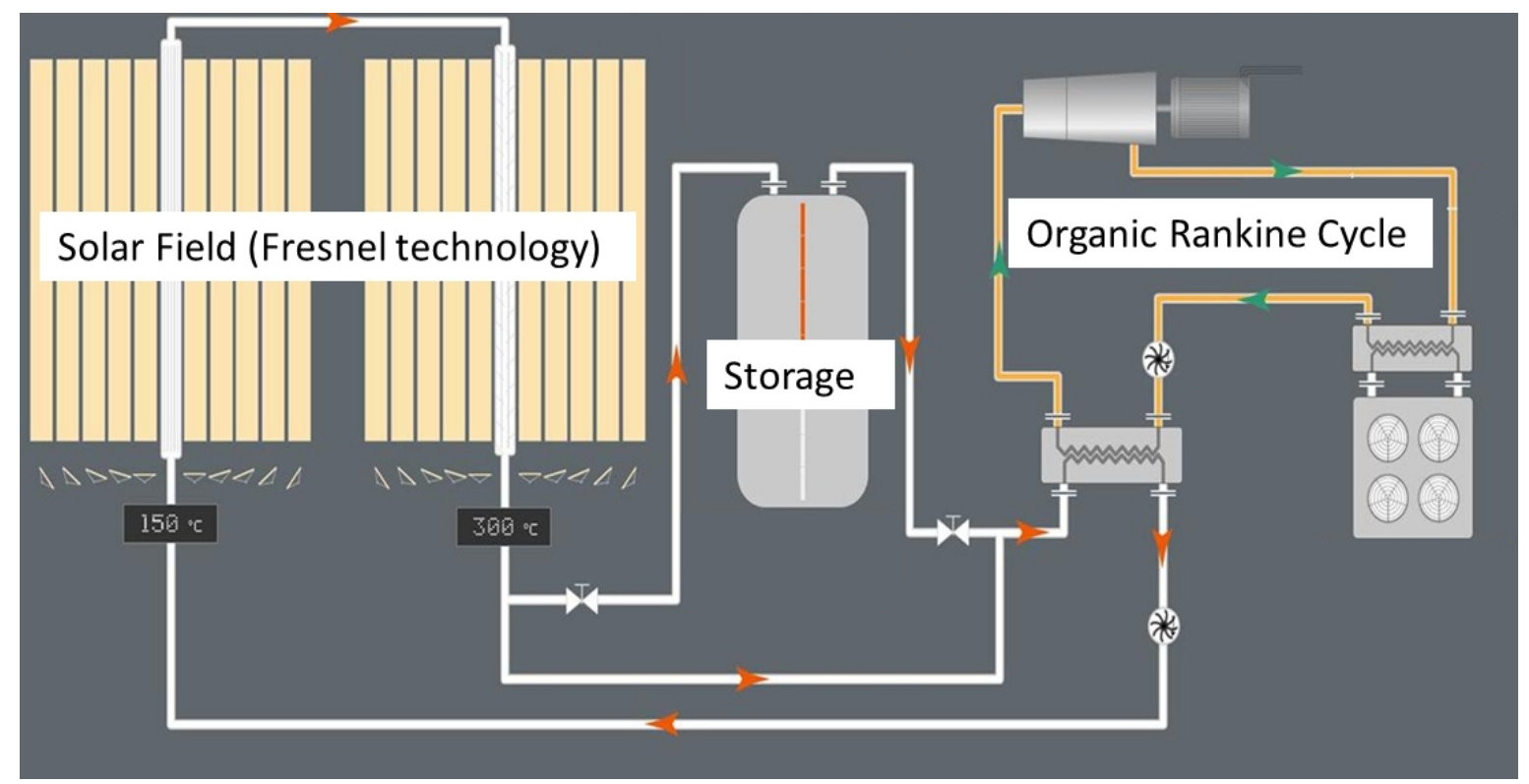

Fig. 4. Simplified flowsheet of the prototype installation

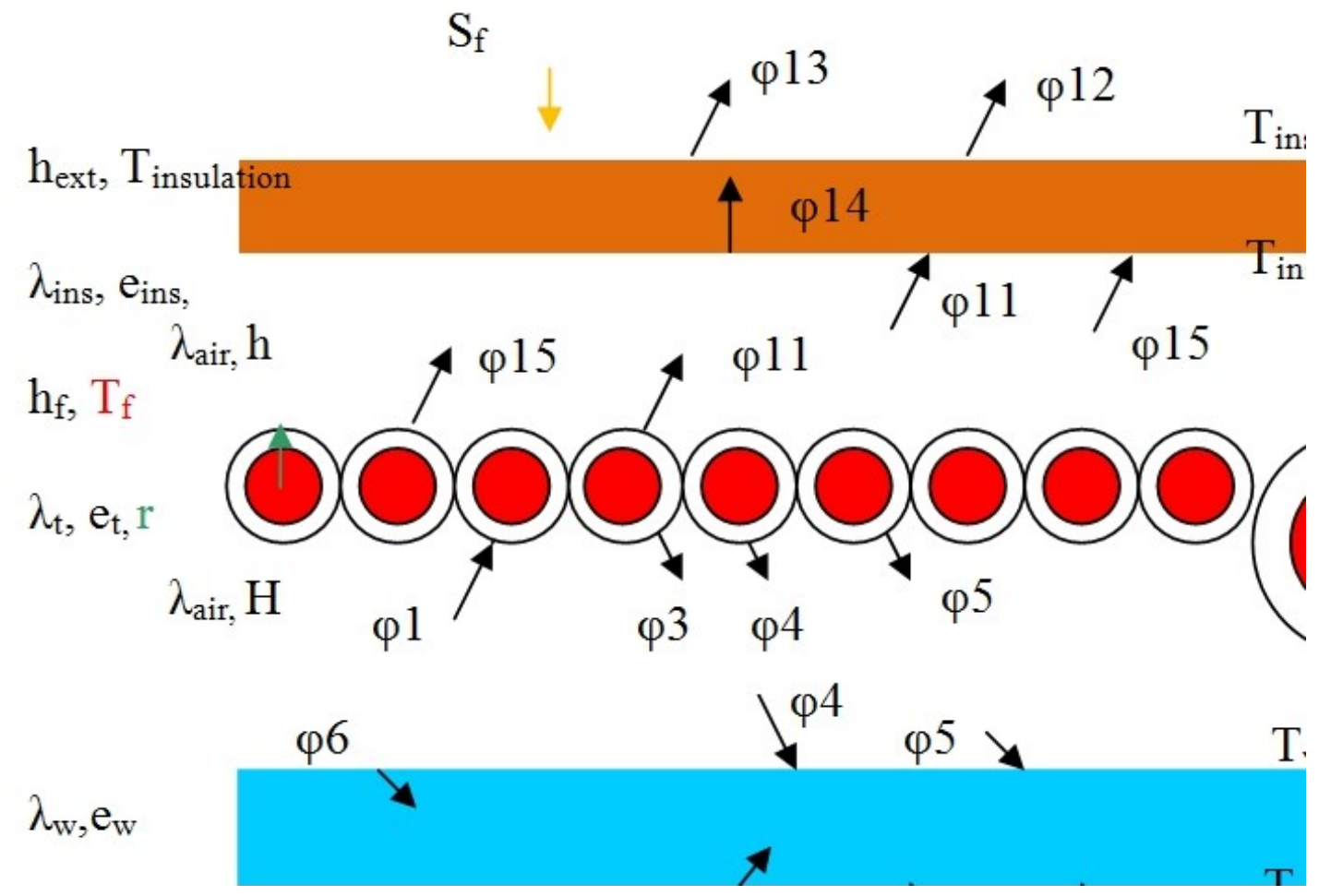

Fig. 5. Detailed scheme of the power exchanges between the receiver tube, the receiver insulation and the receiver window 

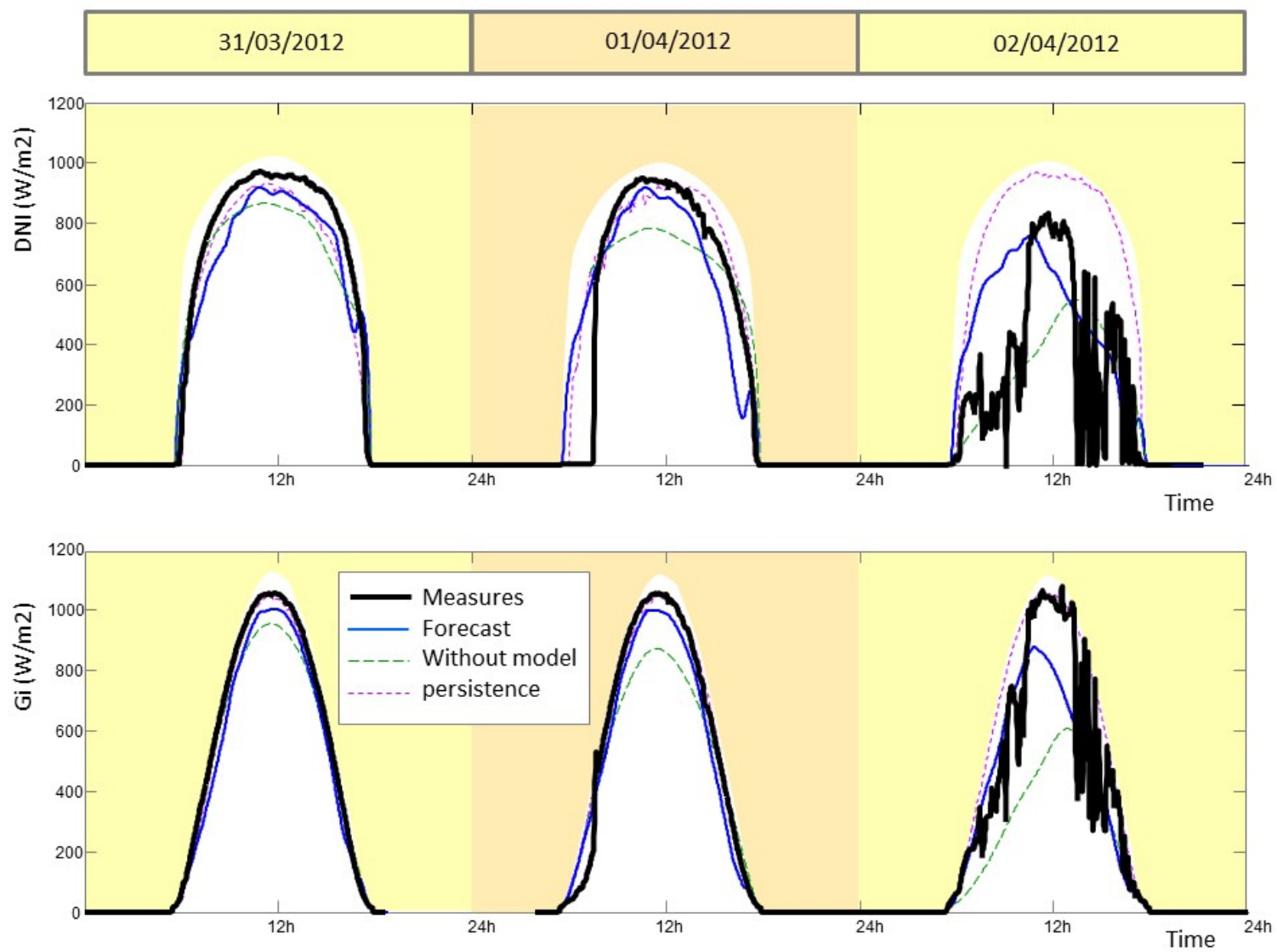

Fig. 6. Example of forecasts on a three-day time scale (DNI and Gi) in CAD site. Measurements are shown as bold curves, the forecasts based on the presented method are shown as solid curves, as well as forecasting without learning (long-dashed curve) and persistence forecast (dashed curve). The white areas correspond to the clear sky model 


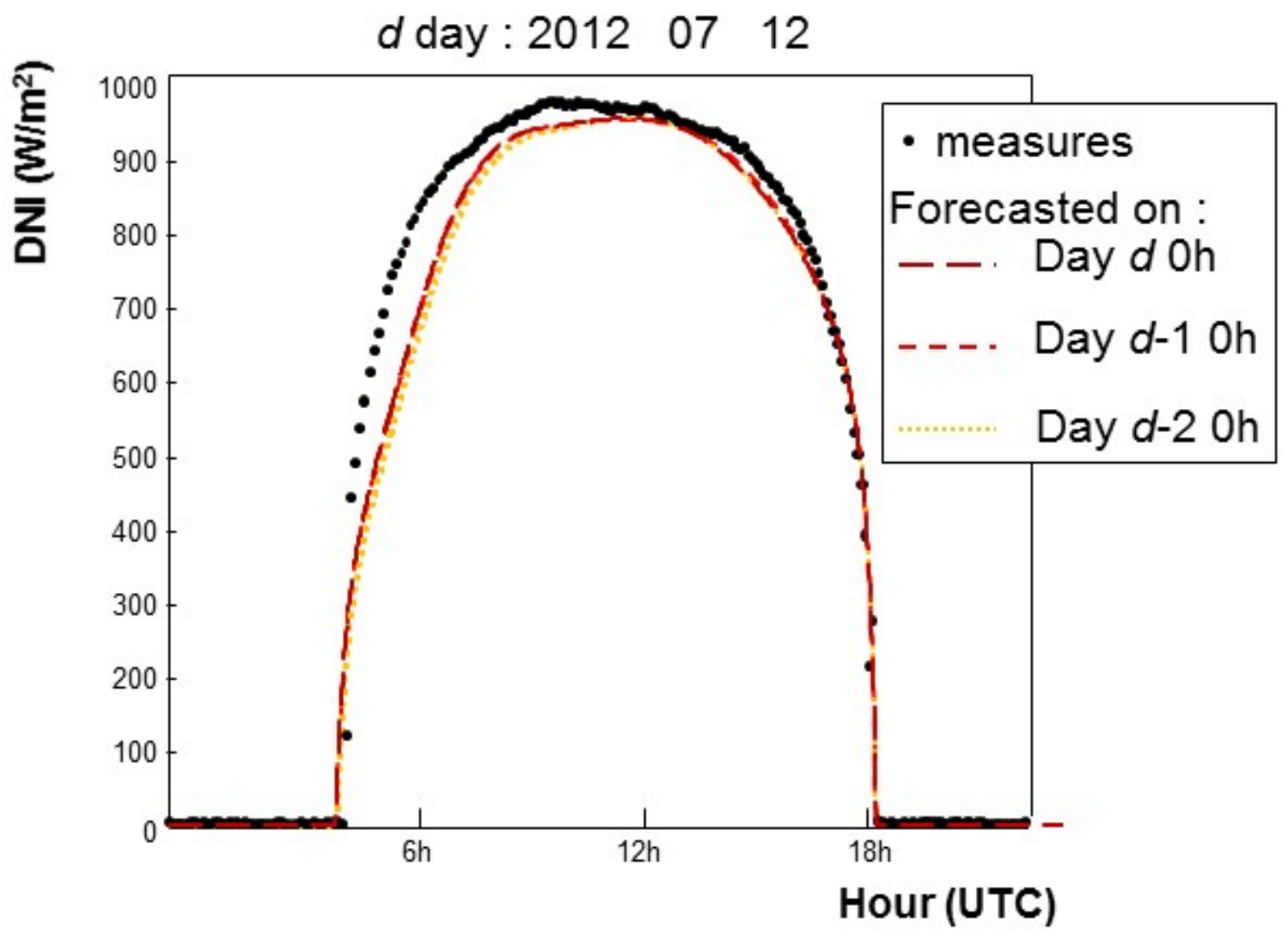

Fig. 7. Forecasted and measured DNI on July $12^{\text {th }} 2012$ at the Cadarache power plant. The black dots correspond to measurements. The dashed lines correspond to forecasts: the darker the line, the shorter the forecasting horizon 


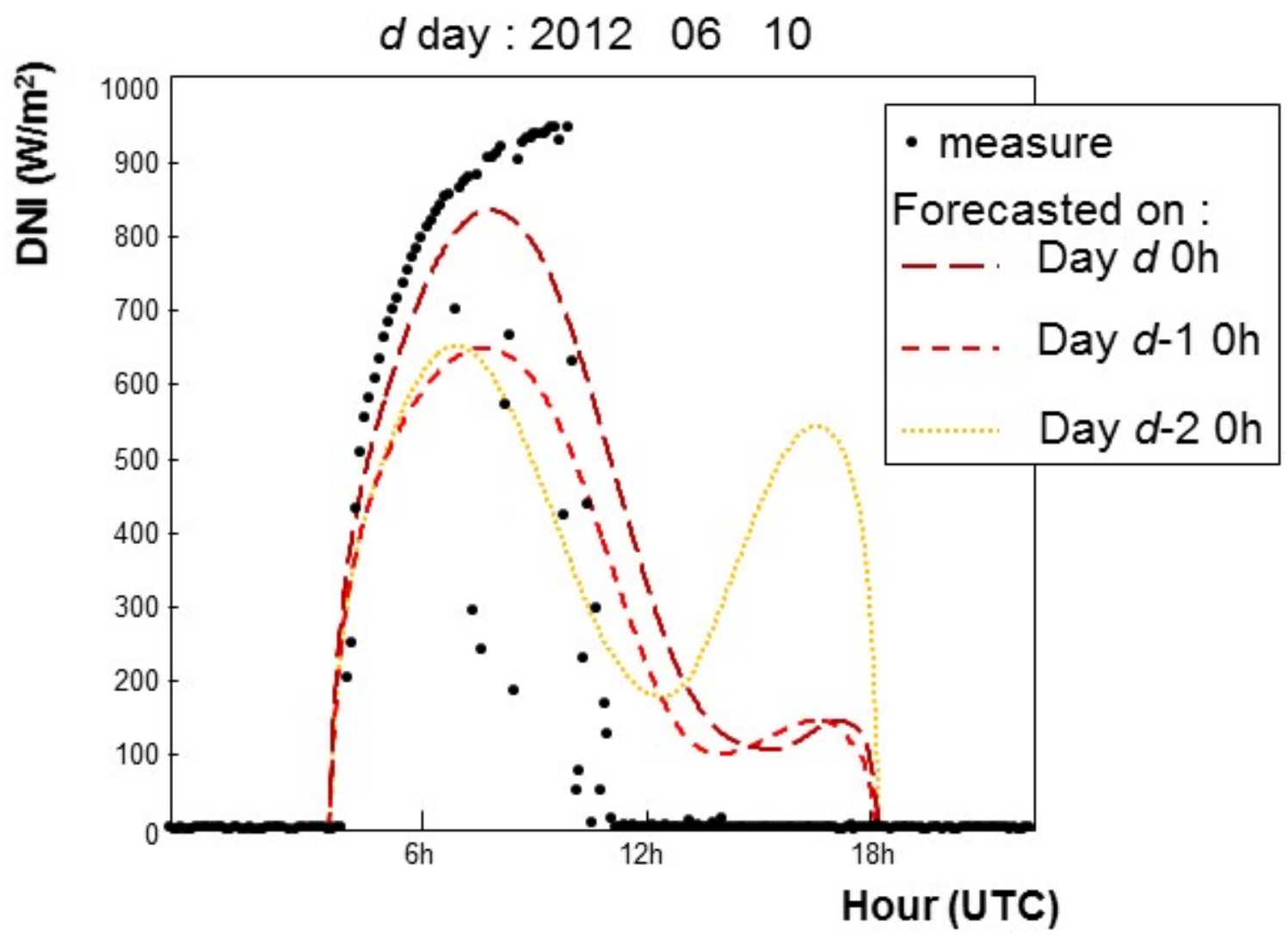

Fig. 8. Forecasted and measured DNI on June $10^{\text {th }} 2012$ at the Cadarache power plant. The black dots correspond to measurements. The dashed lines correspond to forecasts: the darker the line, the shorter the forecasting horizon 


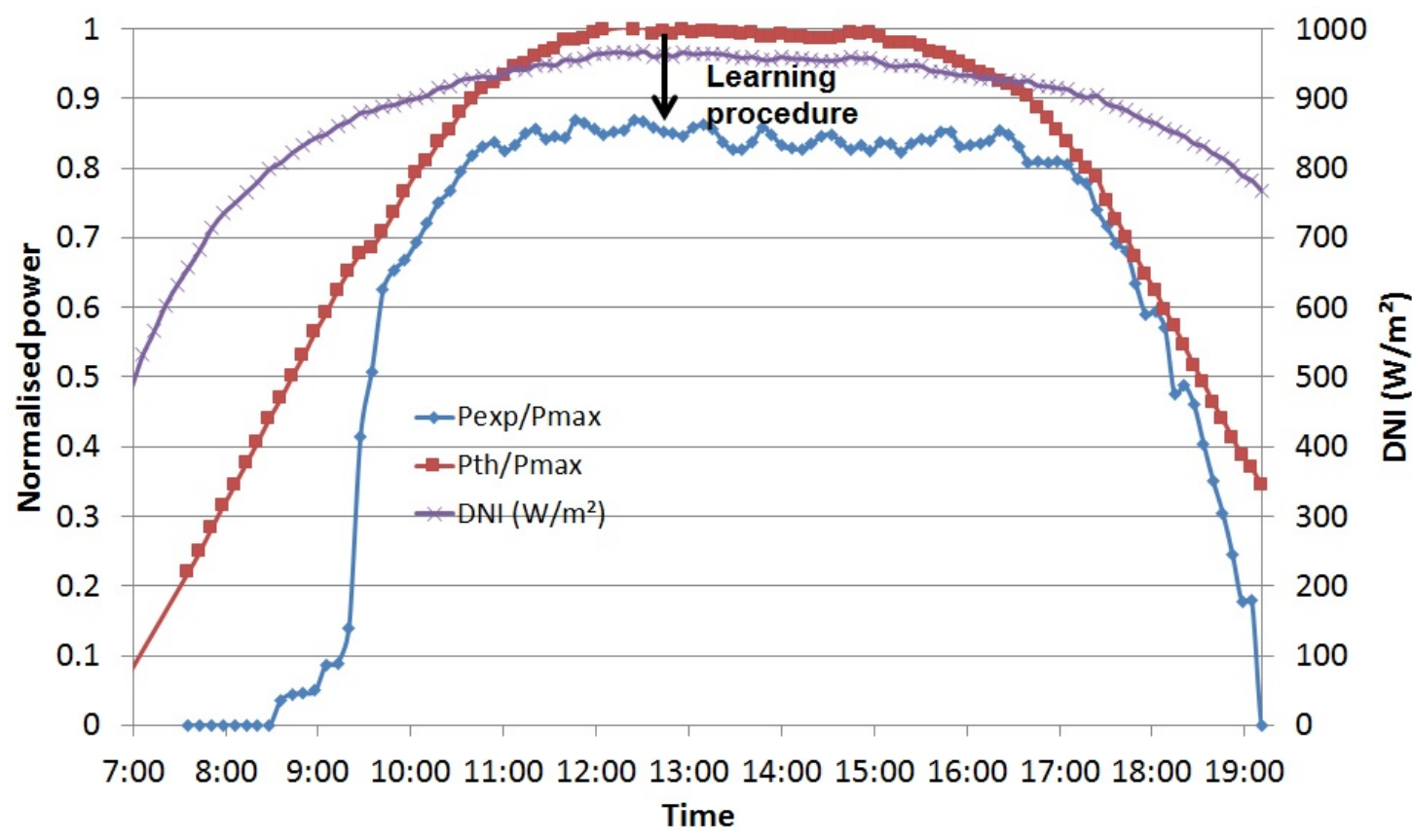

Fig. 9. Normalized theoretical and experimental powers of the plant along with DNI measurement on July, 12th 2012

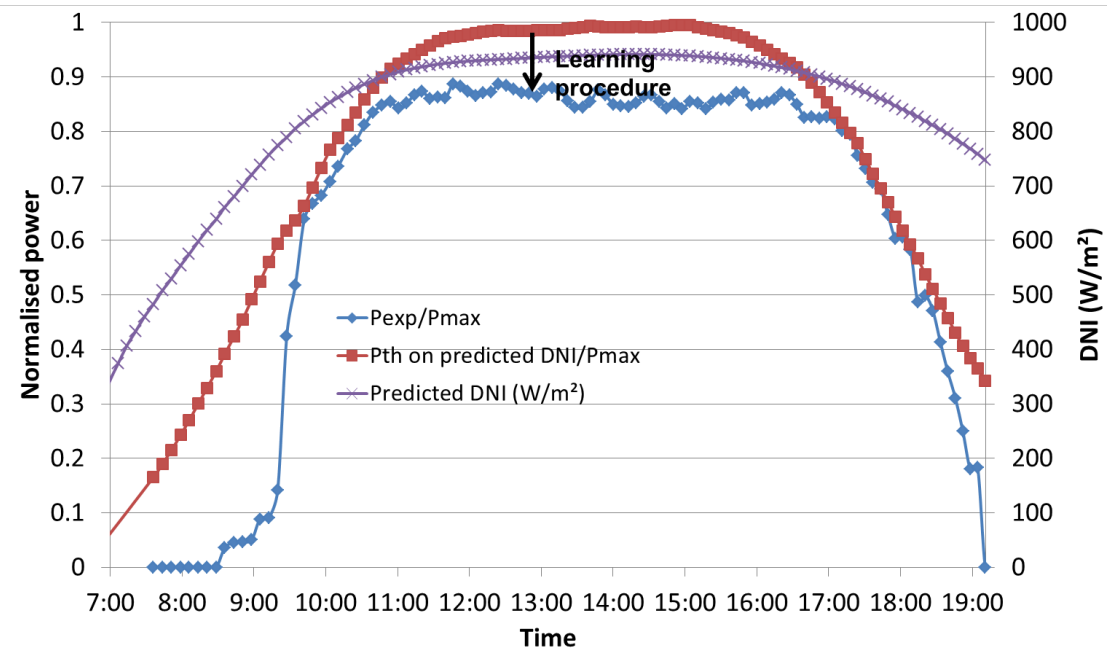

Fig. 10. Normalized theoretical (on forecasted DNI) and experimental powers of the plant along with forecasted DNI on July, $12^{\text {th }} 2012$ 


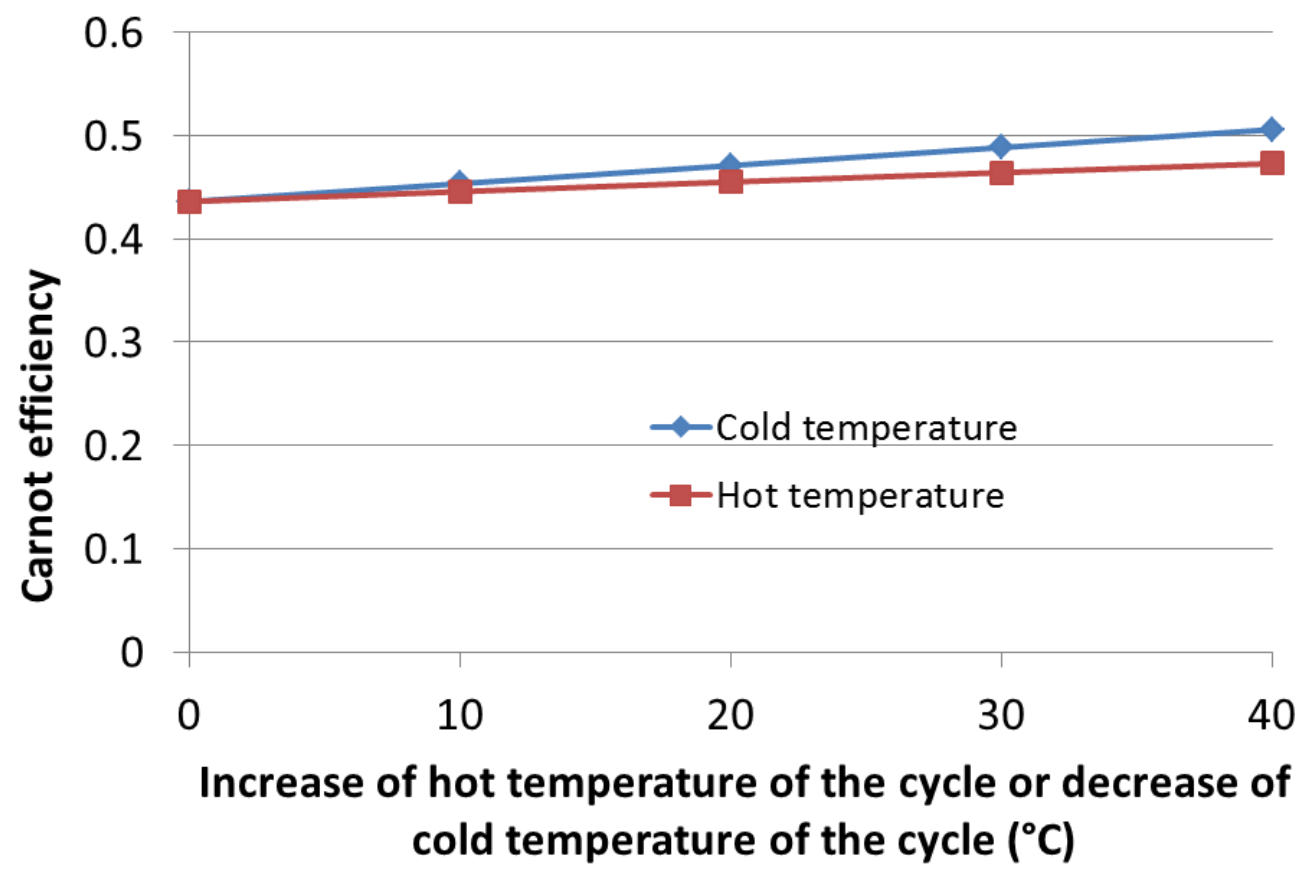

Fig. 11. Influence of the variation of the cold and hot temperatures for a Carnot cycle (reference is Thot $=300{ }^{\circ} \mathrm{C}$ and $\mathbf{T c o l d}=50{ }^{\circ} \mathrm{C}$ ) 


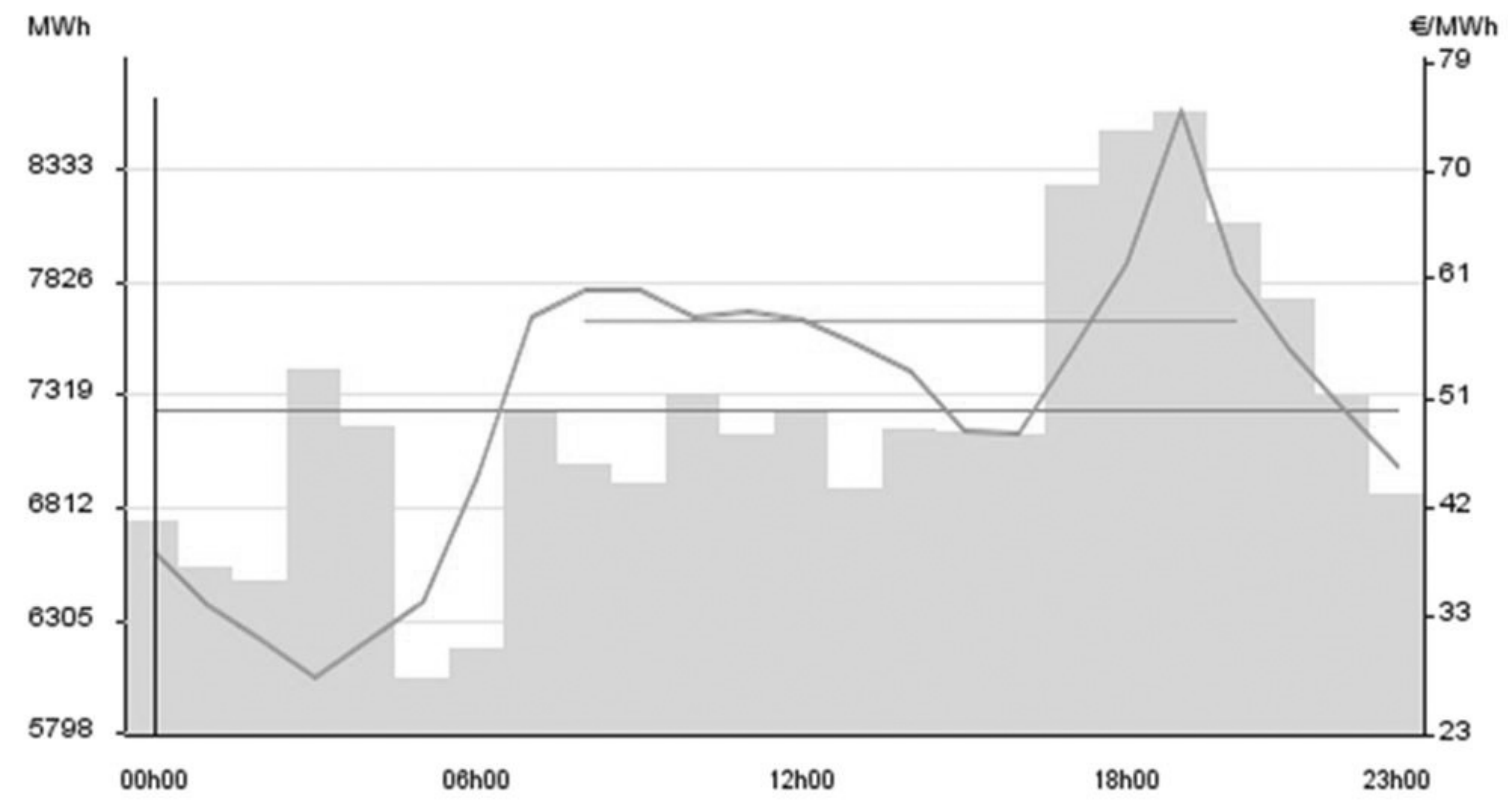

\begin{tabular}{|llll|}
\hline & & Market volumes and prices \\
\hline Volumes & $M W h$ & Base & $49.992 € / M W h$ \\
Prices & $€ / M W h$ & - Peak & $57.534 € / M W h$ \\
\hline
\end{tabular}

Fig. 1. Hourly prices and volumes of Epex Spot for the delivery day of 10 February 2012

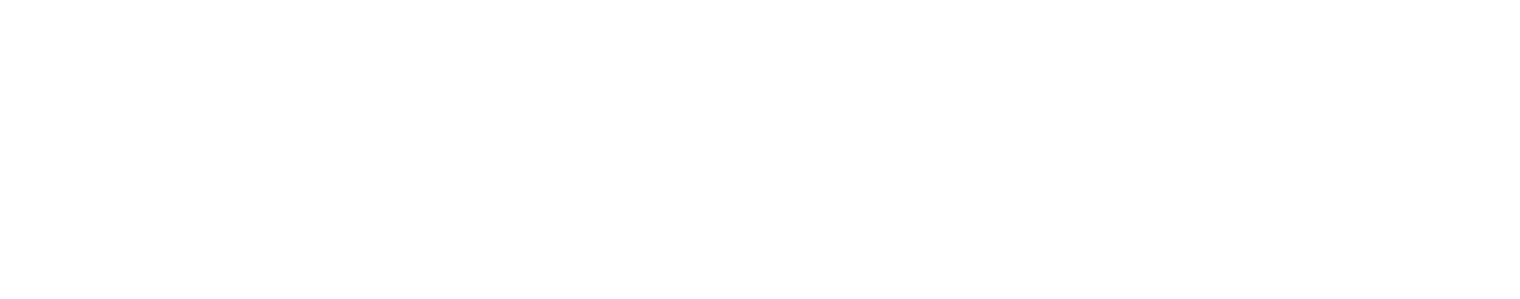

Fig. 2. Functional diagram of the forecasting tool 


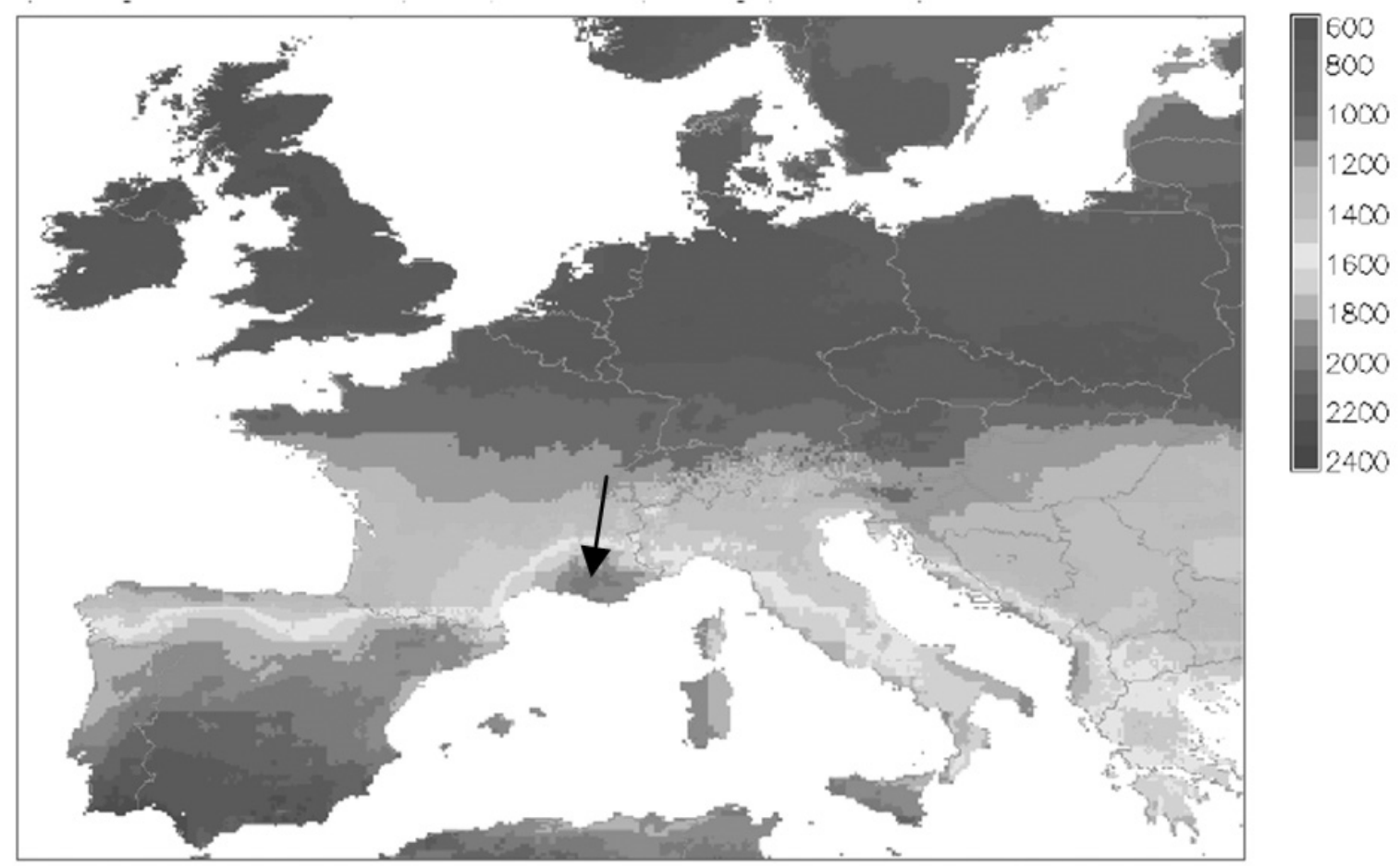

Fig. 3. Yearly sum of Direct Normal Irradiance - average of five databases: Meteonorm, PVGIS,

NASA SSE, Satel-Light, and SOLEMI $\left[\mathrm{kWh} / \mathrm{m}^{2}\right]$. (The arrow points out the solar plant location)

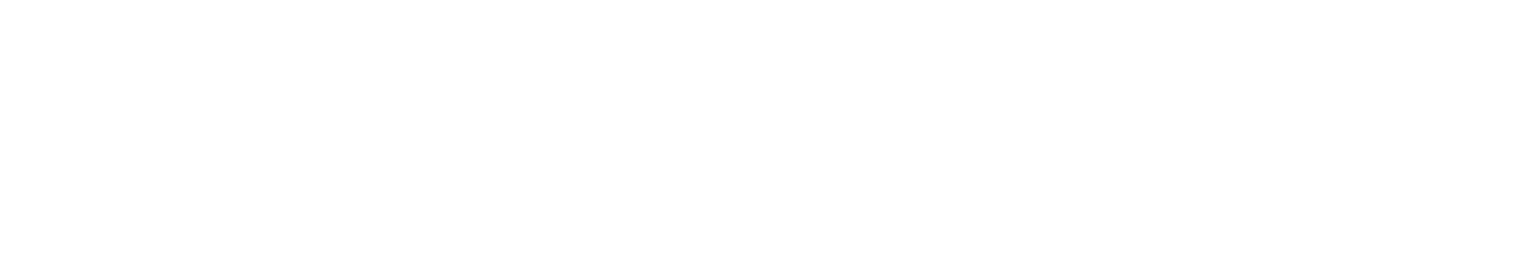

Fig. 4. Simplified flowsheet of the prototype installation 

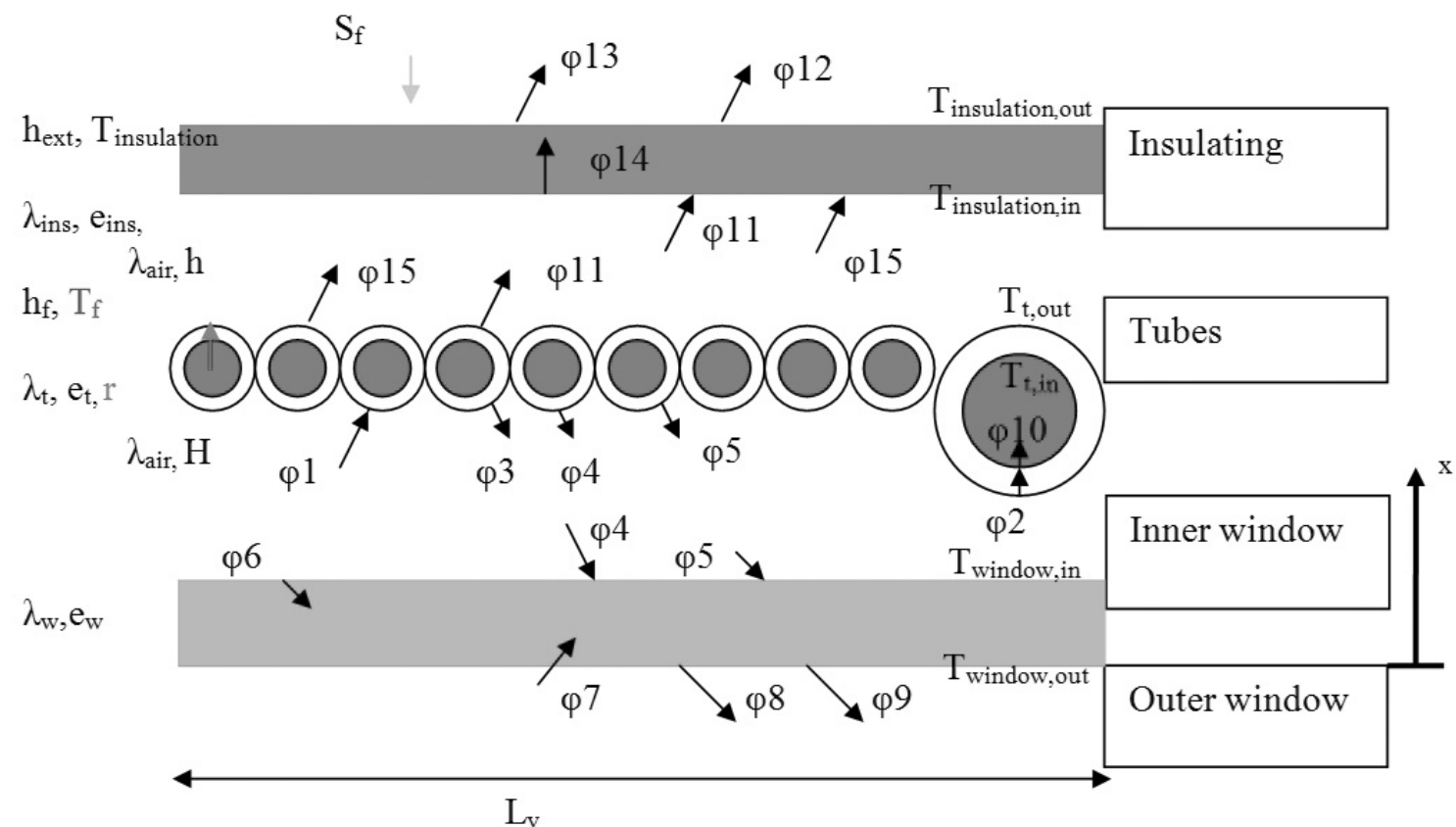

$h_{\text {ext }}$

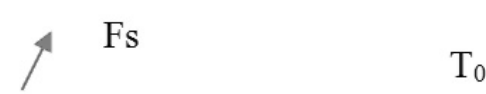

Fig. 5. Detailed scheme of the power exchanges between the receiver tube, the receiver insulation and the receiver window 

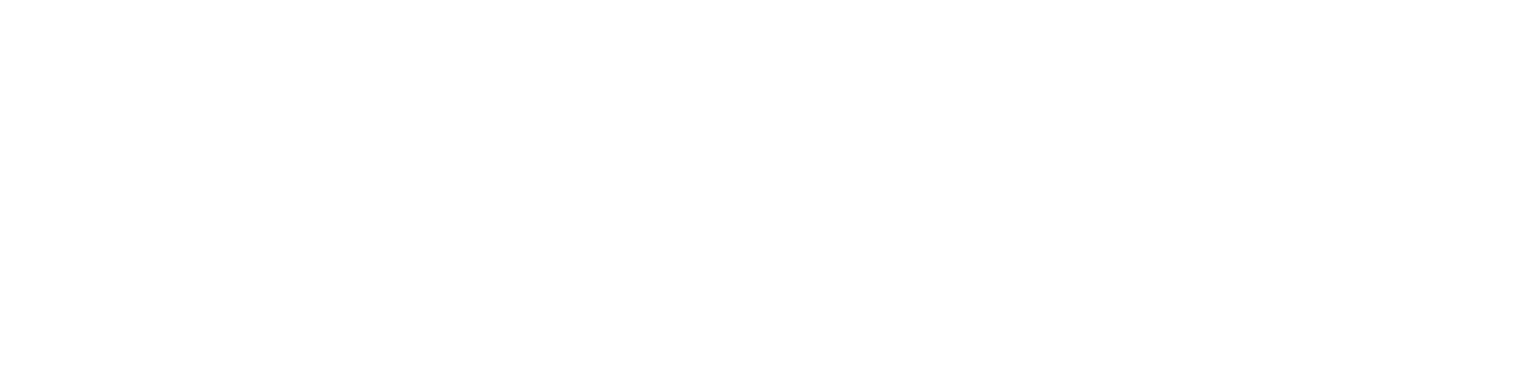

Fig. 6. Example of forecasts on a three-day time scale (DNI and Gi) in CAD site. Measurements are shown as bold curves, the forecasts based on the presented method are shown as solid curves, as well as forecasting without learning (long-dashed curve) and persistence forecast (dashed curve). The white areas correspond to the clear sky model 

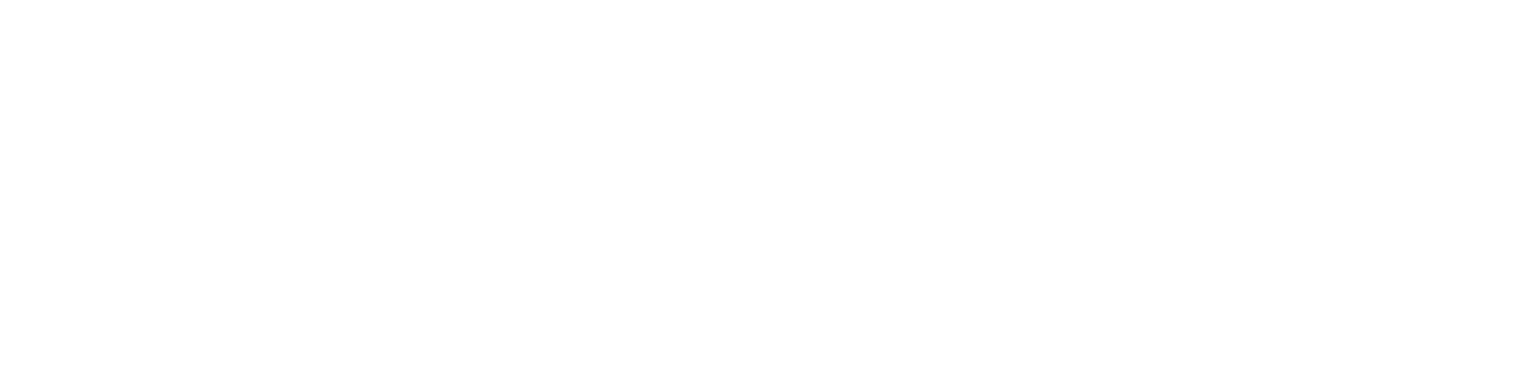

Fig. 7. Forecasted and measured DNI on July $12^{\text {th }} 2012$ at the Cadarache power plant. The black dots correspond to measurements. The dashed lines correspond to forecasts: the darker the line, the shorter the forecasting horizon 

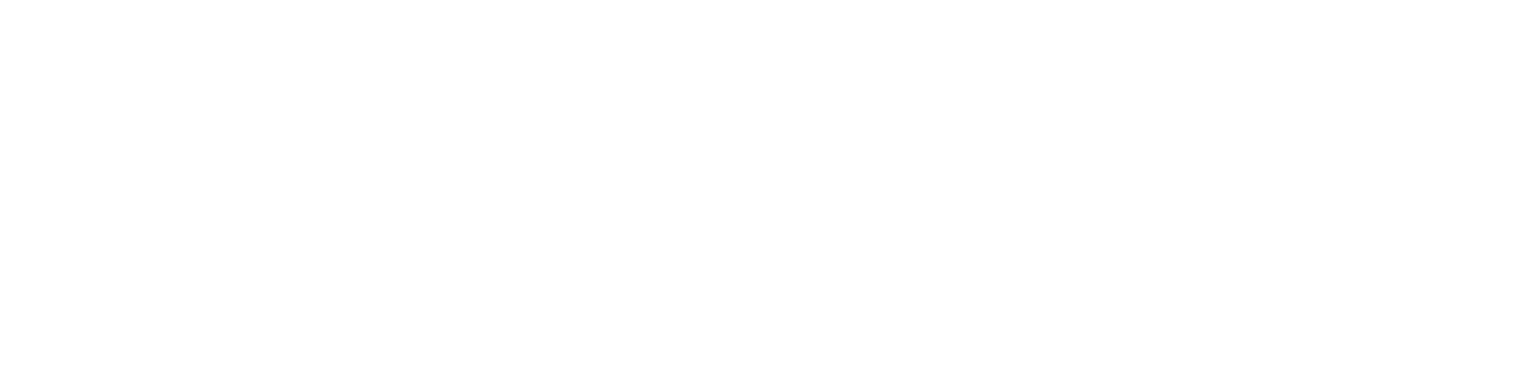

Fig. 8. Forecasted and measured DNI on June $10^{\text {th }} 2012$ at the Cadarache power plant. The black dots correspond to measurements. The dashed lines correspond to forecasts: the darker the line, the shorter the forecasting horizon 

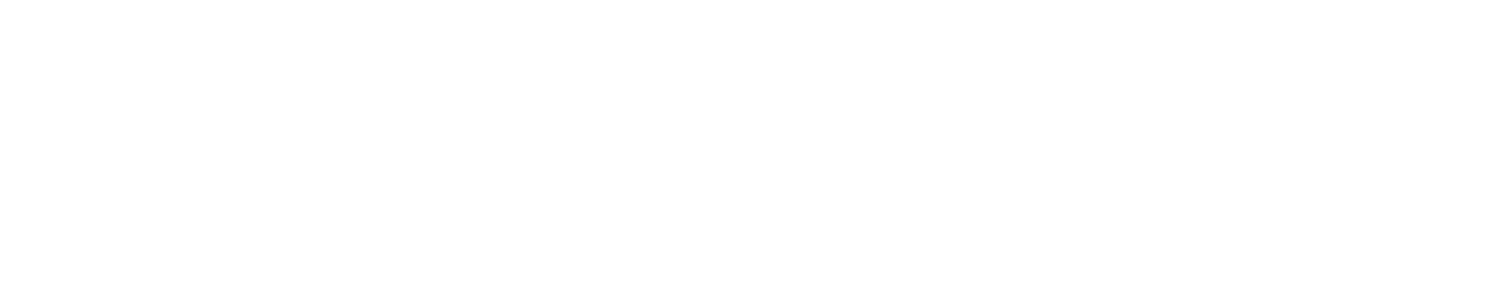

Fig. 9. Normalized theoretical and experimental powers of the plant along with DNI measurement on July, 12th 2012
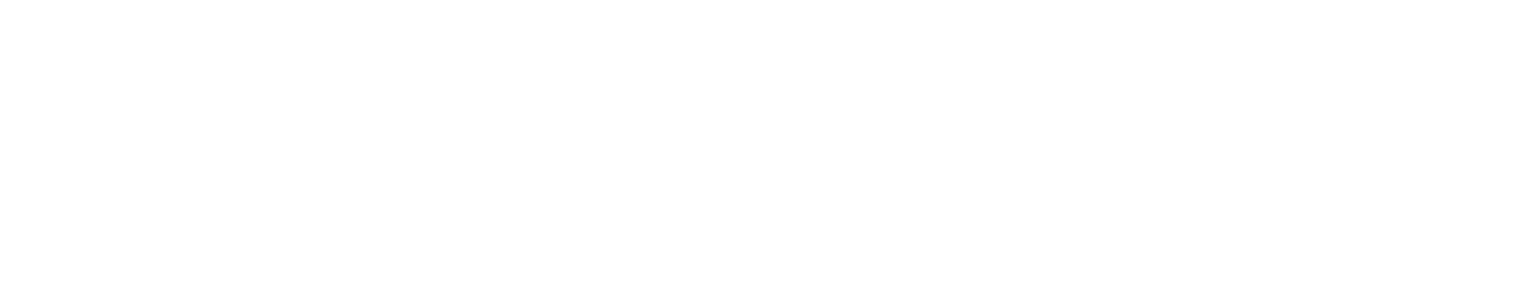

Fig. 10. Normalized theoretical (on forecasted DNI) and experimental powers of the plant along with forecasted DNI on July, $12^{\text {th }} 2012$ 

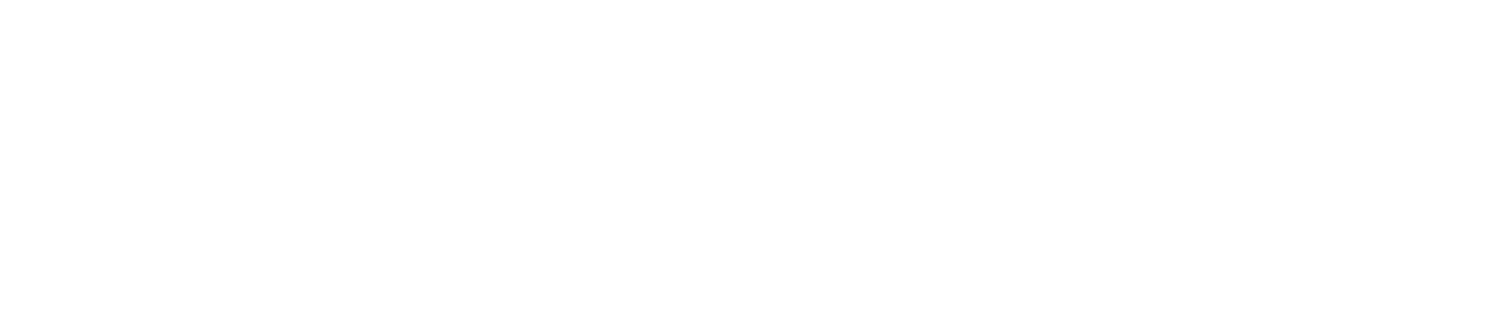

Fig. 11. Influence of the variation of the cold and hot temperatures for a Carnot cycle (reference is Thot $=300{ }^{\circ} \mathrm{C}$ and $\mathrm{Tcold}=50^{\circ} \mathrm{C}$ ) 